\title{
Development of an Empirical Process Model for Adjusted Porosity in Laser-Based Powder Bed Fusion of Ti-6Al-4V
}

Nicole Emminghaus ( $\nabla$ n.emminghaus@lzh.de)

Laser Zentrum Hannover e.V. https://orcid.org/0000-0002-9851-0820

Johanna Paul

Laser Zentrum Hannover e.V.

Christian Hoff

Laser Zentrum Hannover e.V.

Jörg Hermsdorf

Laser Zentrum Hannover e.V.

Stefan Kaierle

Laser Zentrum Hannover e.V.

\section{Research Article}

Keywords: Additive manufacturing, laser-based powder bed fusion, porosity, functionally graded materials, Ti-6Al-4V, design of experiments

Posted Date: June 4th, 2021

DOl: https://doi.org/10.21203/rs.3.rs-546371/v1

License: (c) (i) This work is licensed under a Creative Commons Attribution 4.0 International License. Read Full License

Version of Record: A version of this preprint was published at The International Journal of Advanced Manufacturing Technology on September 15th, 2021. See the published version at https://doi.org/10.1007/s00170-021-07847-0. 


\title{
Development of an empirical process model for adjusted porosity in laser-based powder bed fusion of Ti-6AI-4V
}

\author{
Nicole Emminghaus*, Johanna Paul, Christian Hoff, Jörg Hermsdorf, Stefan Kaierle \\ Laser Zentrum Hannover e.V., Hollerithallee 8, 30419 Hannover, Deutschland (LZH) \\ * Corresponding author: E-mail address: n.emminghaus@lzh.de, https://orcid.org/0000-0002-9851-0820
}

\begin{abstract}
A promising approach to address the mismatch of bone and implant stiffness, leading to the stressshielding phenomenon, is the application of functionally graded materials with adjusted porosity. Although defect formation and porosity in laser-based powder bed fusion of metals (PBF-LB/M) are already widely investigated, so far there is little research on the influences and parameter interactions regarding the pore characteristics. This work therefore aims to provide an empirical process model for the generation of gas porosity in the PBF-LB process of Ti-6Al-4V. For the first time, parts with closed locally adjusted porosity of $\sim 6 \%$ achieved through gaseous pores instead of lack-of-fusion defects or lattice structures were built by PBF-LB. Parameter variation and evaluation of relative density, pore size and sphericity was done in accordance with the design of experiments approach. A parameter set for maximum gas porosity (laser power of $189 \mathrm{~W}$, scanning speed of $375 \mathrm{~mm} / \mathrm{s}$, hatch spacing of $150 \mu \mathrm{m}$ ) was determined for a constant layer thickness of $30 \mu \mathrm{m}$ and a spot diameter of $35 \mu \mathrm{m}$. Tensile tests were conducted with specimens consisting of a core with maximum gas porosity or lack-of-fusion porosity, respectively, and a dense skin as well as fully dense specimens. Whereas lack of fusion defects can lead to significant reduction of stiffness, the elastic modulus remained unchanged when implementing spherical pores. Nevertheless, the found superior strength and ductility of specimens with gas porous core underline the advantages of adjusted porosity for the application in functionally graded materials and lightweight applications.
\end{abstract}

Keywords: Additive manufacturing · laser-based powder bed fusion · porosity · functionally graded materials $\cdot \mathrm{Ti}-6 \mathrm{Al}-4 \mathrm{~V} \cdot$ design of experiments

\section{Abbreviations}

a

AM

$A_{P}$

$\mathrm{BD}$

CAD

CCD

CT

$\mathrm{d}_{0}$

DoE

$E_{P}$

$E_{S}$

$E_{V}$

FGM

LOF

h

$\mathrm{L}_{0}$

$L_{c}$

$\mathrm{L}_{\mathrm{t}}$

O

$P$
Axial distance of star points

Additive Manufacturing

Mean pore area

Build direction

Computer Aided Design

Central composite design

Computer tomography

Initial specimen diameter

Design of experiments

Elastic modulus of porous

material

Elastic modulus of solid material

Volume energy density

Functionally graded materials

Lack of fusion

hatch spacing

Initial measuring length of specimen

Parallel length of specimen

Total length of specimen

Surface area

Laser power
PBF-LB/M Laser-based powder bed fusion of metals

SEM Scanning electron microscopy

$t \quad$ Layer thickness

U Perimeter

UTS Ultimate tensile strength

$v \quad$ Scanning speed

$V \quad$ Volume

YS Yield strength

$\rho_{P} \quad$ Density of porous material

$\rho_{\text {Rel }} \quad$ Relative density

$\rho_{\text {Rel_\% }}$

$\rho_{s}$

$\psi_{3 D}$

$\psi_{2 D}$

Relative density in \%

Density of solid material

Three-dimensional sphericity

Two-dimensional sphericityequivalent

\section{Introduction}

Additive manufacturing (AM) technologies allow the production of individually shaped parts and small lot sizes without additional costs. A popular example of a promising application is the realization of customized implants [1-4]. The most 
commonly used metal AM technology is laserbased powder bed fusion of metals (PBF-LB/M) [5], in which the distributed powder layers are selectively melted by a laser under inert gas atmosphere. PBF-LB offers the advantages of a wide range of processable materials [6-9] and the ability to manufacture high-resolution parts [10]. Furthermore, recycling and reuse of the metallic powder is possible [11-14], increasing the material utilization.

One of the most intensively investigated materials for PBF-LB is Ti-6Al-4V ( $\mathrm{Ti}-6 \mathrm{wt} \% \mathrm{Al}-4 \mathrm{wt} \% \mathrm{~V})$ $[6,15-16]$. The $(\alpha+\beta)$-titanium alloy is known for its low density, high strength, fracture toughness and corrosion resistance as well as excellent biocompatibility [17-19]. It is therefore a suitable material for load bearing implants. However, as the Young's modulus of titanium is $110 \mathrm{GPa}$ while it is only 10 to $30 \mathrm{GPa}$ for human bone, stressshielding is a well-known drawback [20, 21]. By shielding the bone from the stress applied to loadbearing implants, it is insufficiently loaded so that, based on Wolff's law [22], bone resorption is increased and bone atrophy occurs. The resulting eventual loosening of the implant thus leads to a reduction in implant lifetime [20].

To address this challenge and reduce the implant's stiffness, the manufacturing of porous materials has been proposed by Oh et al. [23]. These are characterized by the presence of voids, which can be open or closed and of more or less regular kind [24]. Increased porosity generally reduces the mechanical properties [25], so that an increase of pore size can lead to a reduction of the Young's modulus because of wall thickness thinning [26]. As stated by Gibson and Ashby, the mechanical response of porous material is mostly influenced by the relative density $\rho_{R e l}$, defined as the ratio of the density $\rho_{P}$ of the porous material and the density $\rho_{S}$ of the solid material [27]:

$$
\rho_{R e l}=\frac{\rho_{P}}{\rho_{S}}
$$

According to equation (2), $\rho_{R e l}$ has a quadratic influence on the elastic modulus [25], whereby $E_{P}$ stands for the elastic modulus of the porous material and $E_{S}$ for the one of the solid material.

$$
E_{P}=\left(\frac{\rho_{P}}{\rho_{S}}\right)^{2} E_{S}
$$

Besides the desired reduction of implant stiffness, the side effects of porous structures on other mechanical properties, e.g. ductility, tensile strength, compressive strength and fatigue, can be detrimental and need to be taken into consideration.

Functionally graded materials (FGM) are a topic that has recently attracted growing attention in terms of application in implants and stiffness adjustment. FGM are characterized by internal variations regarding their composition, microstructure or macrostructure across the volume and therefore by graded properties. These different areas can merge continuously or be clearly delimited from one another and are usually graded in a single direction [28]. Additive manufacturing, especially powder bed fusion technologies, are not only capable to overcome the limitations of conventional manufacturing techniques in terms of porosity adjustment, but they also allow the fabrication of complex geometries and therefore cellular materials and lattice structures for FGM. To enable the removal of loose powder after the process, the additively manufactured structures need to exhibit an opencell lattice structure [29]. To achieve a Young's modulus similar to human bone, a Ti-6Al-4V structure with $65 \%$ porosity would be necessary [30]. This can be achieved with different lattice structures, stochastic and non-stochastic, including TPMS structures (triply periodic minimal surfaces), each of which offers different advantages [31]. The open porosity also facilitates bone ingrowth and osseointegration, which, if desired, ensures permanent integration of the implant in the body so that additional cementing of the implant is not necessary [32]. Numerous studies have been conducted to examine the additive manufacturing of open-porous lattice structures for use in biomedical applications (e.g. [29-30, 32- 34]).

However, if bone ingrowth is undesirable, for example with non-permanent implants, opencellular structures are disadvantageous and closed internal pores are preferable. Additionally, open-cellular structures show anisotropic deformation behavior, affected by pore size and shape as well as orientation, arrangement and distribution of pores [35], which can also be a detrimental property. Since powder cannot be removed from closed voids after processing, the application of lattice structures designed by CAD (computer aided design) is not suitable. Instead, porosity needs to be achieved by adjusting the processing parameters. Only few previous works have focused on the generation of closed porosity by powder bed fusion technology. 
Elsayed et al. used DoE (Design of Experiments) to find a combination of process parameters that introduces porosity in a component made of Ti$6 \mathrm{Al}-4 \mathrm{~V}$ high enough to reach the elastic modulus of human bone [36]. Therefore, they used higher laser scanning speeds and lower laser powers than would be necessary for a dense component, so that the powder was not completely melted and lack-of-fusion (LOF) defects occurred. Lin et al. followed a similar approach, but only varied the laser power for a fixed scanning speed $(1250 \mathrm{~mm} / \mathrm{s})$, layer thickness $(30 \mu \mathrm{m})$ and hatch spacing $(10 \mu \mathrm{m})$ [37]. The porosity can thus be also attributed to LOF defects. Cylindrical specimens with a porous core and a dense skin with varying thickness were built. The parts can therefore be regarded as FGM.

Generally, there are two types of pores in parts manufactured by PBF-LB, irregular shaped LOF defects and spherical pores attributed to gas entrapment [38-39]. LOF defects are of elongated, irregular shape and of strongly varying size. They cause higher stress concentrations than spherical gas pores due to the notch effect. Consequently, the mechanical behavior is impaired to a greater extent [40], especially when the load is applied in build direction [41]. On the contrary, gas porosity shows a spherical morphology that is less critical for the propagation of cracks [40]. Its impact on the mechanical properties is also independent of the load direction [41].

So far, there is no study considering the fabrication of functionally graded materials with adjusted porosity by generation of spherical gas pores. These are typically looked at as undesired defects and thus avoided. In consequence, processing maps and models are not designed for obtaining specific pore characteristics but to achieve components with maximum density. They are also lacking broader porosity information like sphericity or mean pore size. The aim of the presented work therefore is to thoroughly investigate the effects of the main processing parameters on these porosity characteristics as well as their interactions. By employment of the DoE approach, an empirical process model is developed allowing the prediction and adjustment of graded porosity. Feasibility of the fabrication of FGM is demonstrated and its influence on tensile properties is studied.

\section{Materials and Methods 2.1 Experimental Materials}

The powder material used in this work was gas atomized Ti-6Al-4V grade 23 powder supplied by
Heraeus additive manufacturing $\mathrm{GmbH}$ with a specified particle size of $15 \mu \mathrm{m}-53 \mu \mathrm{m}$. According to the manufacturer's data sheet, the size distribution of the virgin powder exhibits the Dvalues $22 \mu \mathrm{m}$ (D10), $38 \mu \mathrm{m}$ (D50) and $54 \mu \mathrm{m}$ (D90). Since the reuse of powder is of growing interest for industrial applications, the powder was used after multiple recycling so that a narrower size distribution and a slightly improved flowability can be assumed [5]. The scanning electron microscopy (SEM) analysis (Fig. 1) showed that the powder particles are mainly spherical with a smooth surface and of similar size.

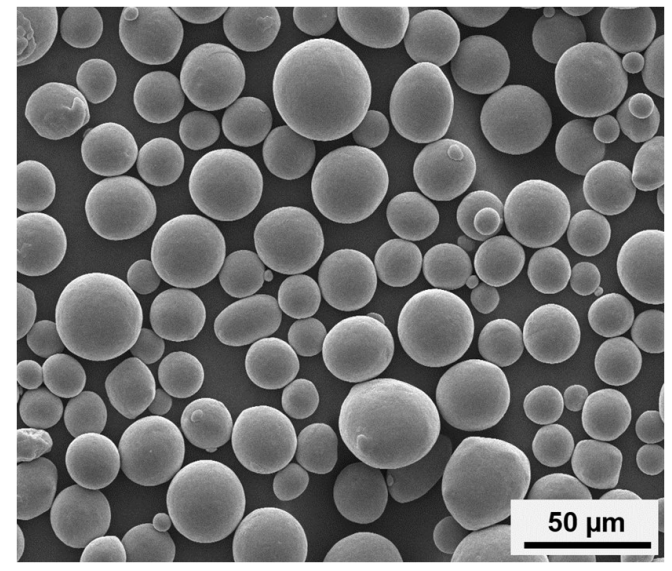

Fig. 1 SEM image of used Ti-6Al-4V powder

\subsection{Experimental Equipment}

The specimens were built on an industrial machine, Lasertec 12 SLM by DMG MORI GmbH (Bielefeld, Germany), that is equipped with a $400 \mathrm{~W}$ ytterbium fiber laser (single mode, continuous wave, wavelength $1070 \mathrm{~nm}$ ). It supplies a high quality laser beam $\left(\mathrm{M}^{2}=1.05\right)$ with a minimum spot diameter of $35 \mu \mathrm{m}$. The process was carried out under argon atmosphere with a residual oxygen content of $0.13 \mathrm{vol} \%-0.15 \mathrm{vol} \%$. A Ti-6Al-4V build plate was used.

The tensile tests were performed according to DIN EN ISO 6892-1:2020-06. They were conducted using a MTS Landmark $100 \mathrm{kN}$ and a MTS axial extensometer with a gauge length of $25 \mathrm{~mm}$. A crosshead speed of $0.42 \mathrm{~mm} / \mathrm{min}$ equivalent to an initial strain rate of $2.5 \times 10^{-4} \mathrm{~s}^{-1}$ was implemented.

\subsection{Experimental Design}

In order to develop the empirical process model that describes the influences on porosity and porosity characteristics, three experimental runs were conducted. Therein, cubic specimens with a side length of $5 \mathrm{~mm}$ were built upon $3 \mathrm{~mm}$ support structures. The experimental design for all runs in accordance with the DoE approach was 
generated using the statistics software $\mathrm{JMP}^{\circledR}$ (SAS Institute Inc.). The first run (screening run) was meant to give an overview over a broad parameter window and to find general parameter settings for high gas porosity. The second run (main run), was conducted to narrow the processing window and was based on the findings of the screening run. As a third run, the verification run was implemented to confirm the results from the previous main run and thus investigate the reproducibility and to refine the statistical model.

Different experimental designs and numbers of specimens were realized for the experimental runs. Table 1 gives an overview of the applied design, specimen number and the levels of the varied factors, i.e. the varied process parameters. For the screening run, a custom design was selected for a number of 50 specimens. To generate a custom design, the statistics software tailors the experimental design for the specific needs, e.g. a given number of specimens and the effects that the user wants to evaluate. For the following two runs, a circumscribed central composite design (CCD) with $\alpha=4 / 3$ (axial distance of star points to the center) was implemented, so that first- and second-order terms, including two-factor interaction effects, can be estimated. Fig. 2 shows a circumscribed CCD. The advantage of this design is that combinations of extreme values are evaded. Within the main run, the central point was repeated four times and all other parameter combinations two times. For the verification run, the main run was repeated with half of the specimens. The verification run served to compare the results between different build jobs and verify that the observed effects are not caused by the build job conduction itself due to possible variation of surrounding factors like temperature or humidity. The mathematical model was fitted based on both, the results from the main as well as from the verification run. A significance level of $5 \%$ was chosen. All not significant terms ( $p$-value $>0.05)$ were excluded under the condition that there were no significant dependent higher order effects following the principle of strong effect heredity. The mathematical model was fitted using the least squares method.

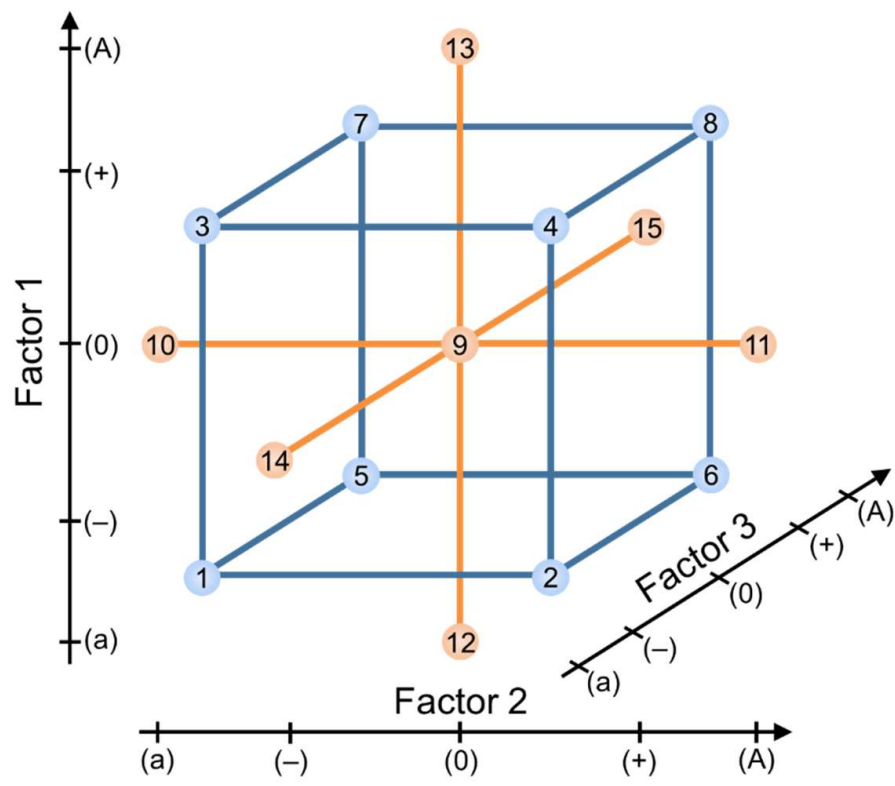

Fig. 2 Central composite design with corner points (1-8), central point (9) and star points (10-15)

Table 1 Experimental runs and their experimental design, specimen number and factor levels

\begin{tabular}{|c|c|c|c|c|c|}
\hline \multirow[b]{2}{*}{ Run } & \multirow[b]{2}{*}{ Design } & \multirow{2}{*}{$\begin{array}{l}\text { Specimen } \\
\text { Number }\end{array}$} & \multicolumn{3}{|c|}{ Factor Levels } \\
\hline & & & $P$ in $W$ & $v$ in $\mathrm{mm} / \mathrm{s}$ & $h$ in $\mu \mathrm{m}$ \\
\hline Screening & $\begin{array}{l}\mathrm{JMP}^{\circledR} \\
\text { Custom }\end{array}$ & 50 & $\begin{array}{c}50,100,150 \\
200,250\end{array}$ & $\begin{array}{c}300,650,1000 \\
1350,1700\end{array}$ & $\begin{array}{c}30,60,90 \\
120,150\end{array}$ \\
\hline Main & $\begin{array}{l}\text { Central } \\
\text { Composite }\end{array}$ & 32 & $\begin{array}{c}80,100,160 \\
220,240\end{array}$ & $\begin{array}{c}200,250,400 \\
550,600\end{array}$ & $\begin{array}{c}30,45,90 \\
135,150\end{array}$ \\
\hline Verification & $\begin{array}{l}\text { Central } \\
\text { Composite }\end{array}$ & 16 & $\begin{array}{c}80,100,160 \\
220,240\end{array}$ & $\begin{array}{c}200,250,400 \\
550,600\end{array}$ & $\begin{array}{c}30,45,90 \\
135,150\end{array}$ \\
\hline
\end{tabular}


As displayed in Table 1, the varied parameters for all conducted experimental runs were laser power $P$, scanning speed $v$ and hatch spacing $h$. The preheating temperature of the build platform and the layer thickness $t$ were kept constant for all experiments at $100{ }^{\circ} \mathrm{C}$ and $30 \mu \mathrm{m}$, respectively. $\mathrm{A}$ cross-hatching strategy with a rotation angle of $67^{\circ}$ between adjacent layers was applied to realize isotropic properties in horizontal direction [42]. The specimens were placed randomly on the build plate to exclude the influence of the position determined by direction of gas flow and recoater movement.

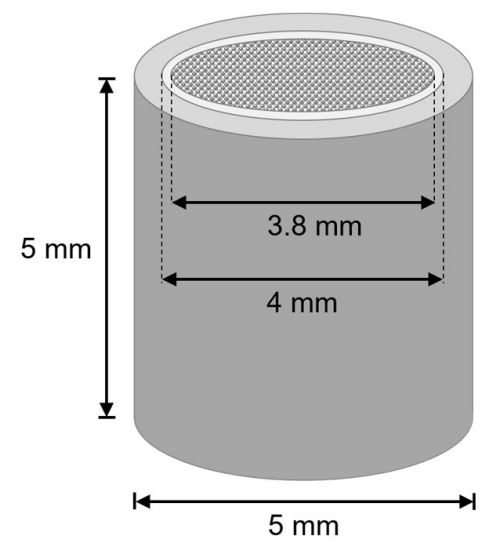

Fig. 3 Geometry of cylindrical specimens with porous core and dense skin

Based on the predictions of the empirical model, cylindrical specimens (height: $5 \mathrm{~mm}, \varnothing=5 \mathrm{~mm}$ ) with a porous core and a dense skin were processed to demonstrate the feasibility of realizing graded structures with the determined processing parameters and to allow a later transfer to cylindrical tensile test samples. The porous core had an effective diameter of $3.8 \mathrm{~mm}$ and the dense skin had an effective thickness of
$0.5 \mathrm{~mm}$. Between them, there was a transition zone with a thickness of $0.1 \mathrm{~mm}$ to ensure sufficient bonding (Fig. 3). This zone was processed with both parameter sets for high and low porosity, respectively.

Finally, tensile test specimens were processed in accordance with DIN EN ISO 6892-1:2020-06. For this purpose, they were built with a slightly larger diameter compared to the final geometry and were subsequently machined by turning to eliminate the influence of the rough as-built surface. As a specimen geometry test shape $B$ was chosen with the parameters given in Table 2. Specimens were built in three conditions: fully dense, with porous core due to gas porosity and with porous core due to LOF defects. The dimensions for the core and transition zone were the same as for the cylindrical specimens. The according processing parameter combinations are provided in Table 3.

Table 2 Tensile test shape B according to DIN EN ISO 6892-1:2020-06

\begin{tabular}{cccc}
\hline $\mathrm{d}_{0}$ & $\mathrm{~L}_{0}$ & $\mathrm{~L}_{\mathrm{c}}$ & $\mathrm{L}_{\mathrm{t}}$ \\
\hline $5 \mathrm{~mm}$ & $25 \mathrm{~mm}$ & $28 \mathrm{~mm}$ & $80 \mathrm{~mm}$ \\
\hline
\end{tabular}

For the demonstration parts and tensile test specimens, different parameter settings were implemented for the core and the skin to generate different densities. They are listed in Table 3. The parameter set that is predicted to lead to maximum gas porosity according to the empirical model was chosen for the porous core. For the skin, a parameter set that leads to high density was used. Three demonstration parts were manufactured to show the feasibility and reproducibility of FGM and five tensile test specimens were manufactured for each modification.

Table 3 Parameter settings for demonstration parts and tensile test specimens

\begin{tabular}{|c|c|c|c|c|c|c|}
\hline \multirow{2}{*}{ Specimen type } & \multicolumn{2}{|c|}{$P$ in $W$} & \multicolumn{2}{|c|}{$v$ in $\mathrm{mm} / \mathrm{s}$} & \multicolumn{2}{|c|}{$h$ in $\mu \mathrm{m}$} \\
\hline & Skin & Core & Skin & Core & Skin & Core \\
\hline Demonstration & 145 & 189 & 1000 & 375 & 80 & 150 \\
\hline Tensile test & 145 & $\begin{array}{c}189 \\
145 \\
50\end{array}$ & 1000 & $\begin{array}{c}375 \\
1000 \\
650\end{array}$ & 80 & $\begin{array}{c}150 \\
80 \\
120\end{array}$ \\
\hline
\end{tabular}

\subsection{Porosity Analysis}

All specimens were cold embedded in epoxy resin (Technovit Epox, Kulzer GmbH, Hanau, Germany), ground and polished (Tegramin, Struers ApS, Ballerup, Denmark). Three crosssections were made for every specimen parallel to the build direction (BD). For analysis of the metallographic cross-sections light microscopy (Olympus BX60 by Olympus Europa SE \& Co. KG) was employed. The single microscopic images were stitched and analyzed using a python script 
developed at Laser Zentrum Hannover (LZH). This script includes the image transformation to black and white with a given threshold value and a subsequent calculation of the response's relative density (ratio of black and white pixels), average pore size and average two-dimensional sphericity-equivalent. The relative density in percentage was calculated according to equation (3).

$$
\rho_{\text {Rel_o }}=\left(1-\frac{\sum \text { Area }_{\text {pores }}}{\text { Area }}\right) \cdot 100 \%
$$

According to Wadell [43], the true threedimensional sphericity $\psi_{30}$ can be calculated by comparing the surface, which a sphere with the same volume $V$ would have, to the actual surface $O$ of the regarded object:

$$
\psi_{3 D}=\frac{\pi^{\frac{1}{3}}(6 V)^{\frac{2}{3}}}{O}
$$

Since the cross-sections only allow a twodimensional representation of the pores, a twodimensional equivalent of the sphericity $\psi_{2 D}$ is needed. Therefore, the ratio of the perimeter of a circle with the same area $A$ and the actual perimeter $U$ is calculated as shown by the following equation:

$$
\psi_{2 D}=\frac{2 \sqrt{\pi A}}{U}
$$

The sphericity and two-dimensional sphericityequivalent are equal to 1 for a sphere and a circle area, respectively.

The demonstrator parts were analyzed using the same procedure as for the cubic specimens as well as computer tomography (CT). This technique enables a three-dimensional insight into the pore morphology, volume and pore distribution within the specimens.

For the evaluation, the volume energy density was used as an additional metric that allows combining the varied processing parameters. It was calculated according to equation (6).

$$
E_{V}=\frac{P}{v h t}
$$

\section{Results}

The results of the described experiments are presented below. This includes the development and verification of an empirical process model from the data obtained in the screening, main and verification run, which describes the relationship between the target values and the factors. The obtained functionally graded demonstration parts are presented. Moreover, a comparison of the tensile properties of specimens manufactured with different parameter combinations and core porosities is given.

\subsection{Screening run}

At low volume energy density, relatively low relative densities occurred. High relative densities were achieved with a medium volume energy density around $100 \mathrm{~J} / \mathrm{mm}^{3}$ (Fig.4). At higher volume energy densities, specimens with very different relative densities were found. As Fig. 4 shows, the sphericity-equivalent increases with increasing volume energy density. High porosity of over $10 \%$ is only achievable with irregular shaped non-spherical pores, i.e. LOF defects.

This is also demonstrated by the cross-sections (Fig. 5). For all specimens, the pores were randomly distributed within the specimen volume. The mean sphericity-equivalent was between 0.79 $(P=100 \mathrm{~W}, v=1350 \mathrm{~mm} / \mathrm{s}, h=150 \mu \mathrm{m})$ and 0.93 $(P=100 \mathrm{~W}, v=650 \mathrm{~mm} / \mathrm{s}, h=30 \mu \mathrm{m})$. For specimens with a mean sphericity-equivalent below 0.89 , LOF porosity could be seen in the cross-sections. With a mean sphericity-equivalent of 0.90 , high relative densities of over $99.70 \%$ occurred. For mean sphericity-equivalents of over 0.91, there were both high and low-density specimens and the microscopic images showed gas porosity. A transition range of the mean sphericity-equivalent of 0.89 to 0.91 could be defined. LOF porosity occurs for lower and gas porosity for higher values.

The evaluation of the screening run showed that for high spherical porosity, low scanning speeds and medium to high laser powers are favorable, whereby there is a strong interaction effect between these two parameters based on the resulting volume energy density. The hatch spacing showed a smaller influence. With an increasing hatch spacing, the relative density and sphericity-equivalent decrease. To enable a more precise prediction of the porosity characteristics for gas porosity, the main and verification run were subsequently conducted. 


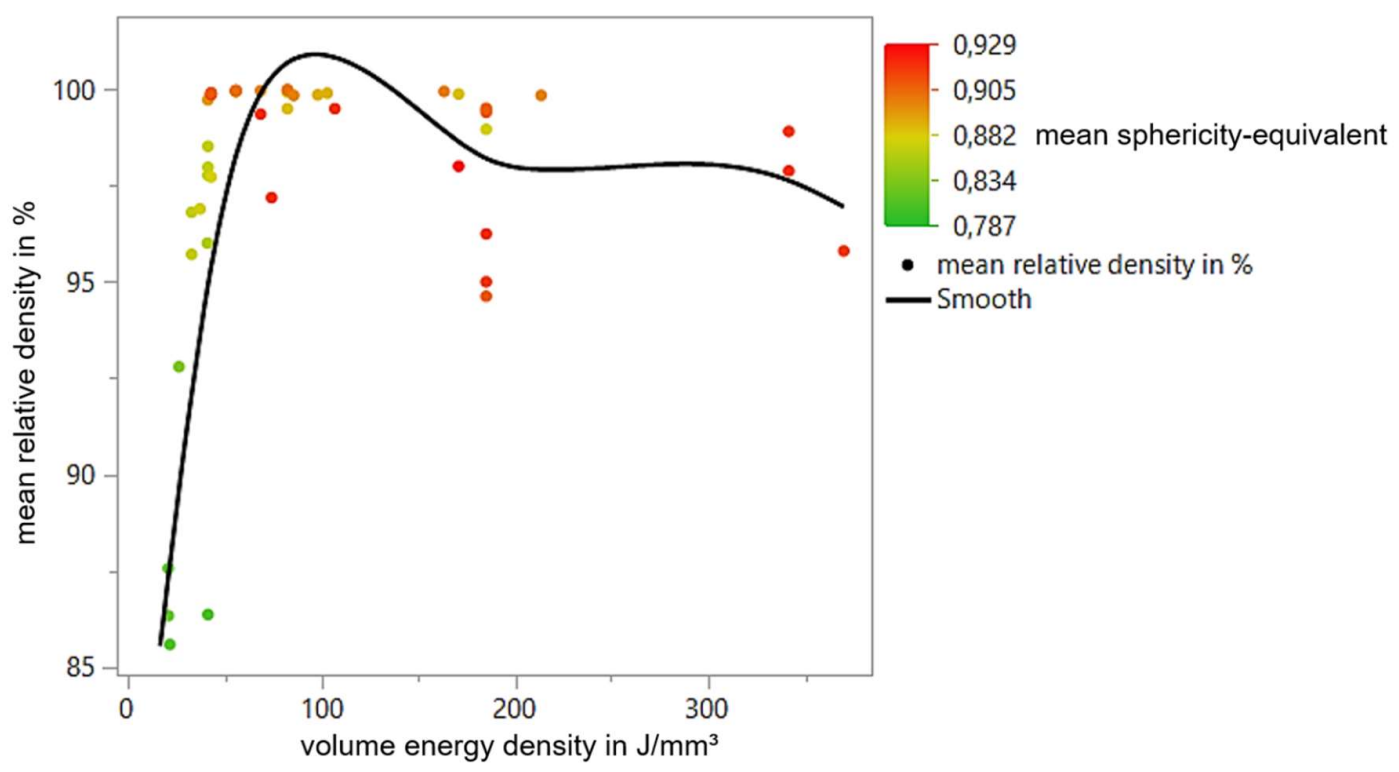

Fig. 4 Mean relative density in dependence of applied volume energy density; mean sphericity-equivalent colorcoded, cubic spline with lambda $=0.05$ used as smoother

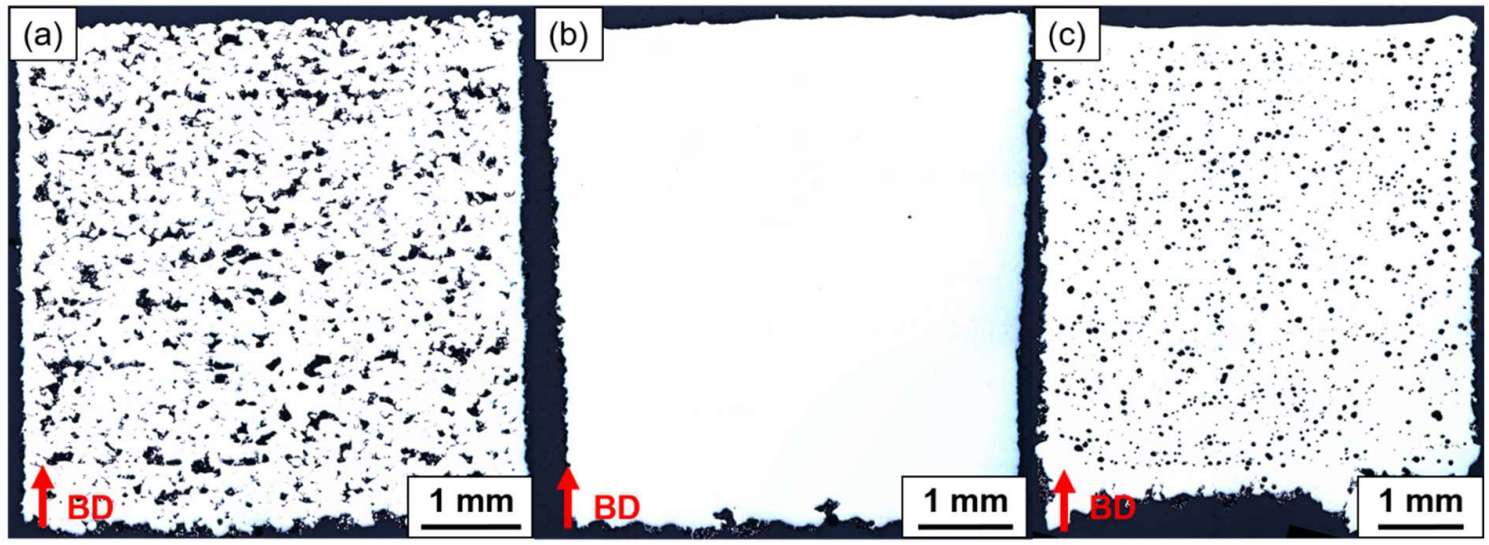

Fig. 5: Light microscopy images of cross-sections: (a) LOF porosity $(P=100 \mathrm{~W}, v=1350 \mathrm{~mm} / \mathrm{s}, h=120 \mu \mathrm{m}),(\mathrm{b})$ nearly fully dense $(P=200 \mathrm{~W}, v=1350 \mathrm{~mm} / \mathrm{s}, h=60 \mu \mathrm{m})$, (c) gas porosity $(P=100 \mathrm{~W}, v=300 \mathrm{~mm} / \mathrm{s}, h=60 \mu \mathrm{m})$; red arrow indicates build direction.

\subsection{Main and verification run}

Based on the findings from the screening run, lower scanning speeds and a slightly smaller range of the laser power where chosen for the main and verification run (Table 2). This way, the parameter window for the desired spherical porosity was investigated more closely to maximize the porosity for later application in FGM.

In general, the verification run led to results comparable to the main experimental run, with a mean relative density of $97.11 \%$ in the main run and $97.10 \%$ in the verification run. However, the parameter combinations for which maximum or minimum values of the porosity characteristics were obtained were partly different for the two runs. Furthermore, it was noticed, that the deviation of properties between specimens built with the same parameter settings were larger than the deviations within a specimen between the evaluated cross-sections. This high variation of properties explains the observed differences between the two runs. Nevertheless, the maximum spherical porosity achieved was comparable, with $92.52 \%$ relative density in the main run and $92.62 \%$ in the verification run (in both runs for $P=100 \mathrm{~W}, v=400 \mathrm{~mm} / \mathrm{s}, h=90$ $\mu \mathrm{m})$.

Based on the results for the pore characteristics obtained within the main and the verification run, an empirical model was developed to enable the prediction and adjustment of spherical porosity. 


\subsection{Empirical model}

All terms that were not significant according to their $p$-value were removed from the model, except for those terms on which higher order effects depended (principle of strong effect heredity). The parameter estimates, as well as their standard error, t-ratios (estimates divided by their standard error) and the respective $p$-values are provided in Table 5 . For the relative density

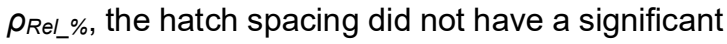
influence but remained in the model because the dependent interaction effect of hatch spacing and laser power was significant. The interaction effect of laser power and scanning speed was also significant while the one between scanning speed and hatch spacing was not. Furthermore, laser power and scanning speed also had a quadratic influence on the relative density, as it can be seen in the prediction equation (7) in the last two terms and in Table 5. This equation shows the parameter estimates, i.e. the coefficients in front of the different terms, which provide information on the influence of the different effects. It can be seen that the quadratic effect of the laser power has the strongest influence on the relative density with a parameter estimate of $2.87 \%$. Besides the insignificant hatch spacing with a parameter estimate of $-0.46 \%$, the linear effect of the scanning speed is the weakest $(1.02 \%)$. The model can be visualized by the contour plots (Fig. 6). It can be seen that there is an optimum area of minimum relative density (maximum porosity) for a scanning speed between $325 \mathrm{~mm} / \mathrm{s}$ and $425 \mathrm{~mm} / \mathrm{s}$ and laser power between $150 \mathrm{~W}$ and $190 \mathrm{~W}$. At scanning speeds under $500 \mathrm{~mm} / \mathrm{s}$, there is a stronger influence of the laser power. For low laser powers under $125 \mathrm{~W}$, the mean relative density is nearly independent of the hatch spacing but for higher powers, it decreases with increasing hatch spacing. It is also visible that the influence of the laser power is stronger at higher hatch spacings. In general, low relative density can be obtained for medium laser power of around $150 \mathrm{~W}$ and high hatch spacings over $100 \mu \mathrm{m}$.

$$
\begin{aligned}
\rho_{\text {Rel_o }}=94.99 \% & -1.14 \% \cdot \frac{P-160 \mathrm{~W}}{80 \mathrm{~W}}+1.02 \% \cdot \frac{v-400 \frac{\mathrm{mm}}{\mathrm{s}}}{200 \frac{\mathrm{mm}}{\mathrm{s}}}-0.46 \% \cdot \frac{h-90 \mu \mathrm{m}}{60 \mu \mathrm{m}} \\
& -1.26 \% \cdot \frac{P-160 \mathrm{~W}}{80 \mathrm{~W}} \cdot \frac{v-400 \frac{\mathrm{mm}}{\mathrm{s}}}{200 \frac{\mathrm{mm}}{\mathrm{s}}}-1.10 \% \cdot \frac{P-160 \mathrm{~W}}{80 \mathrm{~W}} \cdot \frac{h-90 \mu \mathrm{m}}{60 \mu \mathrm{m}} \\
& +2.87 \% \cdot\left(\frac{P-160 \mathrm{~W}}{80 \mathrm{~W}}\right)^{2}+2.24 \% \cdot\left(\frac{v-400 \frac{\mathrm{mm}}{\mathrm{s}}}{200 \frac{\mathrm{mm}}{\mathrm{s}}}\right)^{2}
\end{aligned}
$$
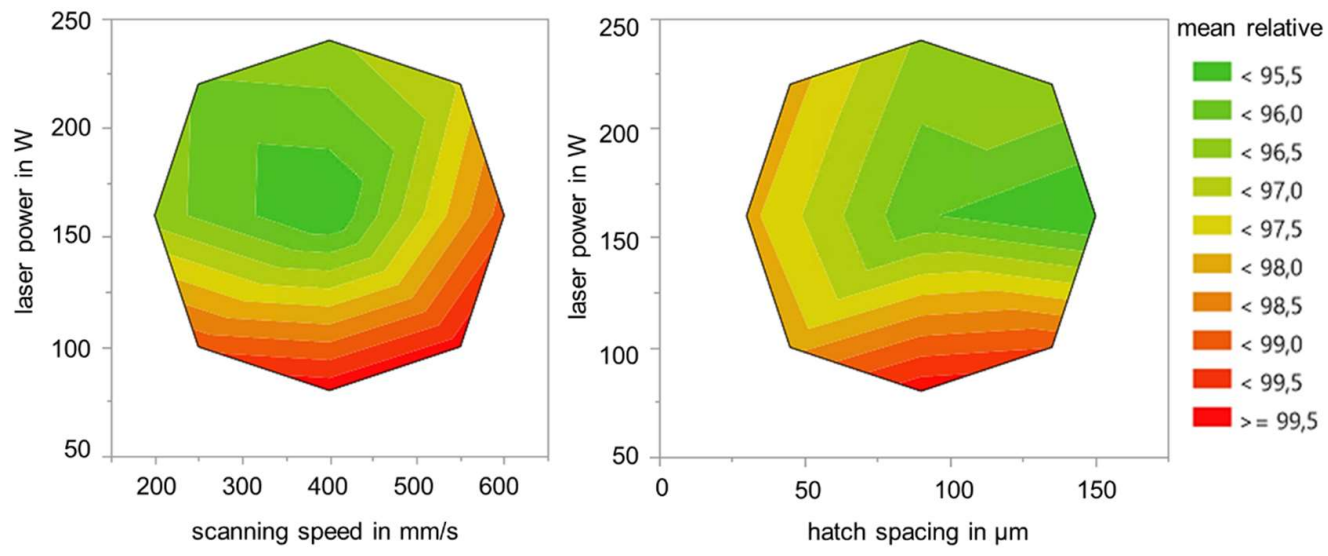

Fig. 6 Contour plots for mean relative density in dependence of laser power, scanning speed and hatch spacing

The sphericity-equivalent $\psi_{2 D}$ only depended on the laser power. The linear as well as the quadratic influence of this parameter were significant according to their p-values (Table 5). Equation (8) represents the prediction equation. According to the empirical model, a maximum sphericity of 0.92 can be achieved for a laser power of $200 \mathrm{~W}$.

$$
\begin{aligned}
& \psi_{2 \mathrm{D}}=0.92+0.01 \cdot \frac{P-160 \mathrm{~W}}{80 \mathrm{~W}}-0.01 \\
& \left(\frac{P-160 \mathrm{~W}}{80 \mathrm{~W}}\right)^{2}
\end{aligned}
$$




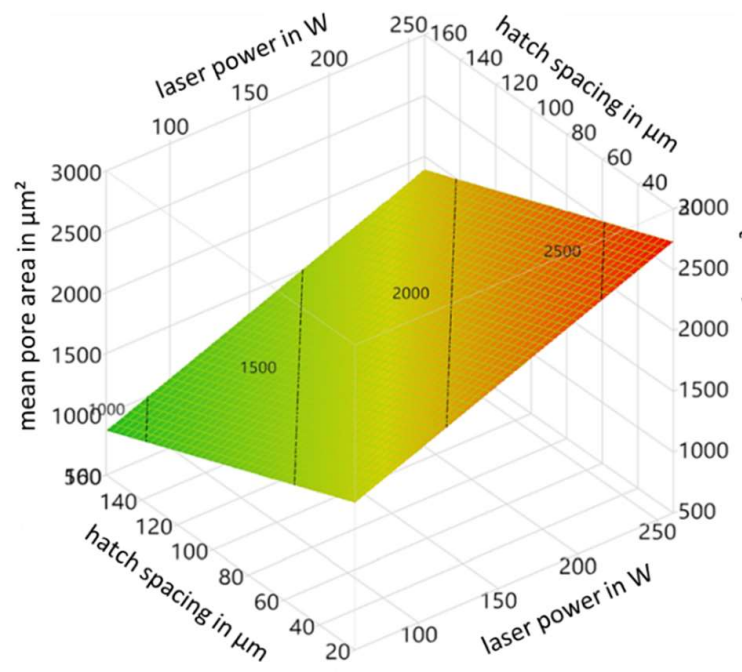

Fig. 7 Response surface of mean pore area in dependence of laser power and hatch spacing

For the mean pore area $A_{P}$ the prediction equation (9) and Table 5 show that only the linear effects of laser power and hatch spacing are significant whereby the influence of the laser power is stronger. The pore size increases with increasing laser power and decreasing hatch spacing without reaching a maximum or minimum. This is also illustrated in Fig. 7.

$$
\begin{aligned}
& A_{\mathrm{P}}=1799.08 \mu \mathrm{m}^{2}+411.29 \mu \mathrm{m}^{2} . \\
& \frac{P-160 \mathrm{~W}}{80 \mathrm{~W}}-359.26 \mu \mathrm{m}^{2} \cdot \frac{h-90 \mu \mathrm{m}}{60 \mu \mathrm{m}}
\end{aligned}
$$

Since the aim of this study was to obtain maximum spherical porosity to reduce the stiffness, the parameter setting for the demonstration parts was chosen according to the predicted relative density. Here, a minimum can be realized with $P=189 \mathrm{~W}$, $v=375 \mathrm{~mm} / \mathrm{s}$ and $h=150 \mu \mathrm{m}$. For this parameter combination, the porosity characteristics given in Table 4 are predicted by the developed model.

Table 4 Predicted pore characteristics for maximized gas porosity

\begin{tabular}{ccc}
\hline$\rho_{\text {ReI_\% in } \%}$ & $\psi_{2 D}$ & $A_{P}$ in $\mu m^{2}$ \\
\hline $94.06 \pm 1.01$ & $0.92 \pm 0.00^{*}$ & $1588.91 \pm$ \\
& 404.84 \\
\hline
\end{tabular}

\begin{tabular}{|c|c|c|c|c|c|}
\hline Model & Term & Estimate & Std. Error & t-Ratio & $p$-Value \\
\hline \multirow{8}{*}{$\rho_{\text {Rel_\% }}$} & Intercept & 94.99 & 0.39 & 246.66 & $<0.0001$ \\
\hline & laser power ${ }^{2}$ & 2.87 & 0.56 & 5.09 & $<0.0001$ \\
\hline & scanning speed ${ }^{2}$ & 2.24 & 0.56 & 3.98 & 0.0003 \\
\hline & laser power-scanning speed & -1.26 & 0.49 & -2.58 & 0.0135 \\
\hline & laser power & -1.14 & 0.30 & -3.76 & 0.0005 \\
\hline & laser power-hatch spacing & -1.10 & 0.49 & -2.26 & 0.0296 \\
\hline & scanning speed & 1.02 & 0.30 & 3.37 & 0.0017 \\
\hline & hatch spacing & -0.46 & 0.30 & -1.50 & 0.1412 \\
\hline \multirow{3}{*}{$\psi_{2 D}$} & Intercept & 0.924 & 0.002 & 407.14 & $<0.0001$ \\
\hline & laser power & -0.010 & 0.004 & -2.44 & 0.0188 \\
\hline & laser power ${ }^{2}$ & 0.006 & 0.002 & 2.77 & 0.0081 \\
\hline \multirow{3}{*}{$A_{P}$} & Intercept & 1799.08 & 103.32 & 17.41 & $<0.0001$ \\
\hline & laser power & 411.29 & 162.09 & 2.54 & 0.0147 \\
\hline & hatch spacing & -359.26 & 162.09 & -2.22 & 0.0318 \\
\hline
\end{tabular}

Table 5 Parameter estimates of the fitted models

\subsection{Functionally graded demonstration parts}

The cylindrical specimens with dense skin and porous core could all successfully be realized with the determined parameters for high spherical porosity. No significant differences between the three specimens could be observed. The density was evaluated for the entire part as well as only for the core. For the core a mean relative density of $94.39 \%$ and for the entire part a mean relative density of $96.11 \%$ was obtained, which was higher due to the inclusion of the dense skin. Fig. 8 shows a metallographic cross-section (a) as well as a CT image (b) with analysis of pore volumes. The porous core can be clearly distinguished from the dense skin. The analysis of the pore volume shows a homogeneous color distribution within the core. This means, that the majority of pores within the core are of a similar size (blue and green) and there are only a few exceptionally large pores (orange and red). 

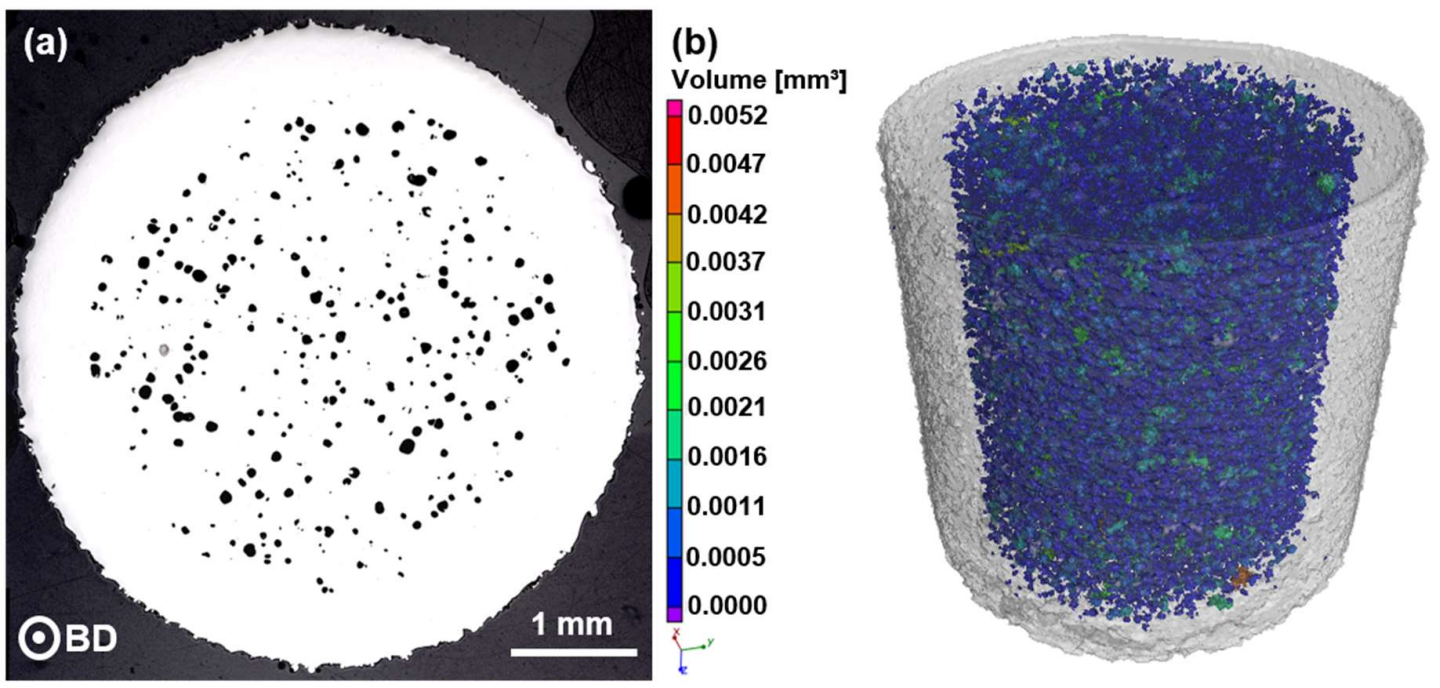

Fig. 8 FGM demonstrator part: (a) Cross-section perpendicular to build direction; (b) CT image with pore analysis

\subsection{Tensile tests}

Tensile tests were conducted for specimens with three different conditions: fully dense, dense skin and porous core with gas pores and dense skin with porous core with LOF defects. The used implemented processing parameters were selected based on the machine manufacturers recommendations and based on previous results leading to maximum gas porosity $(\sim 6 \%)$ and high LOF porosity $(\sim 15 \%)$, respectively (Table 3$)$. Fig. 9 shows the results regarding ultimate tensile strength (UTS), yield strength (YS), the elongation at break and the elastic modulus. The detailed values of all specimens can be found in Table 5 . It can be seen that the specimens with gas pores had the highest strength while the lowest strength was achieved for the specimens with a LOF core. However, the dense specimens showed the smallest standard deviation of the strength values.
Regarding the elongation at break, a similar trend could be observed in comparison to the strength. Although one of the fully dense specimens had a significantly larger elongation of over $0.10 \mathrm{~mm} / \mathrm{mm}$, the other specimens all showed elongations between 0.03 and $0.05 \mathrm{~mm} / \mathrm{mm}$. In contrast, specimens with a gas porous core showed larger elongations between 0.03 and $0.07 \mathrm{~mm} / \mathrm{mm}$, the specimens with LOF core showed significantly smaller elongations below $0.02 \mathrm{~mm} / \mathrm{mm}$. Fully dense and gas porous specimens showed the same mean elastic modulus of $110.0 \mathrm{GPa}$ with a small standard deviation whereas a significant reduction of the elastic modulus could only be achieved by the porous core with LOF defects (74.6 GPa). This is equivalent to a stiffness decrease of $32.2 \%$. For this specimen modification the standard deviation was also larger than for the fully dense or gas porous specimens. 
(a)
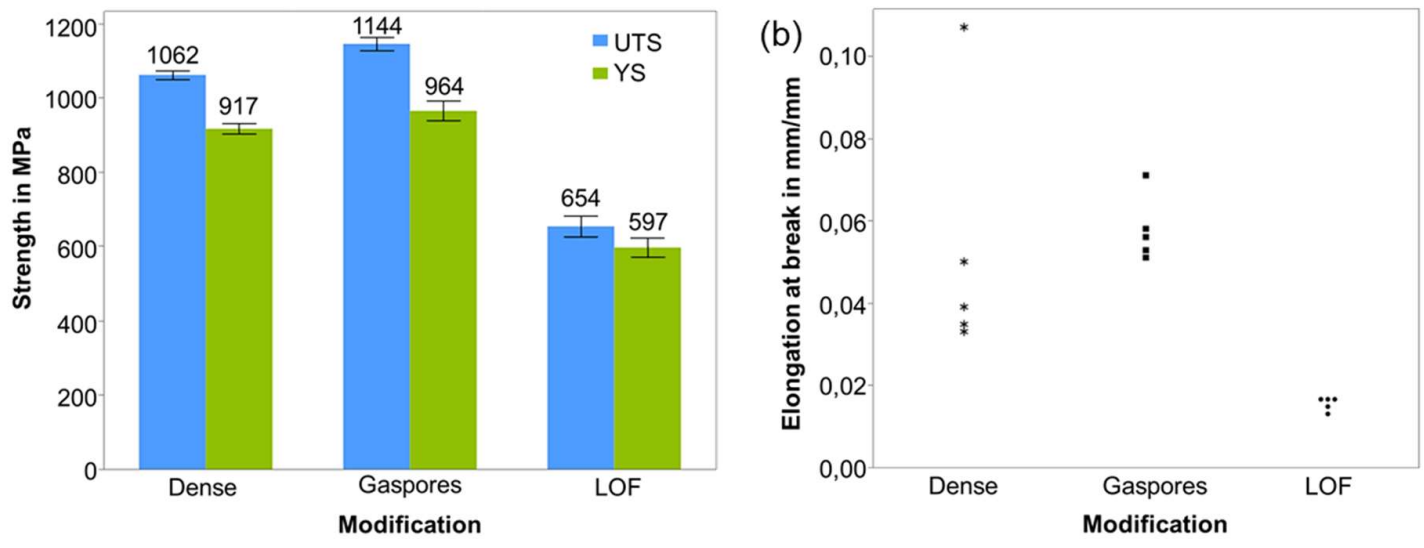

(c)

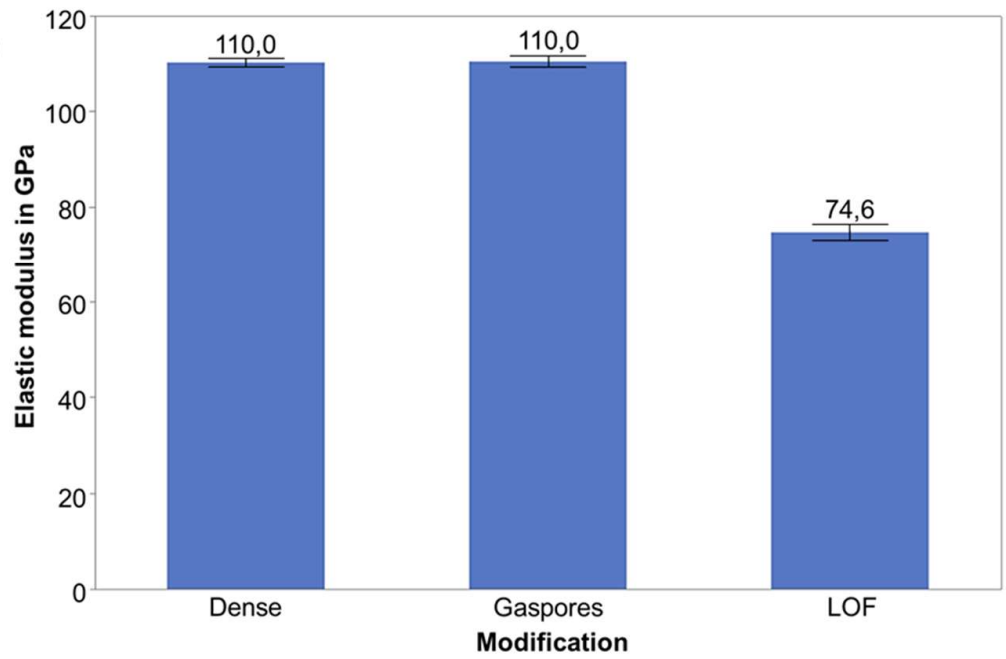

Fig. 9 Tensile test results: (a) Ultimate tensile strength (UTS) and yield strength (YS) with marked standard deviation; (b) elongation at break; (c) elastic modulus with marked standard deviation

Table 5 Results of tensile tests for the three modifications dense, gas porous core and core with LOF defects

\begin{tabular}{|c|c|c|c|c|c|}
\hline & $\begin{array}{l}\text { Specimen- } \\
\text { ID }\end{array}$ & $\begin{array}{l}\text { Elastic Modulus } \\
\text { in GPa }\end{array}$ & $\begin{array}{l}\text { Yield Strength } \\
\text { in } \mathrm{MPa}\end{array}$ & $\begin{array}{l}\text { Ultimate Tensile } \\
\text { Strength in MPa }\end{array}$ & $\begin{array}{l}\text { Elongation at break in } \\
\mathrm{mm} / \mathrm{mm}\end{array}$ \\
\hline \multirow{5}{*}{ Dense } & D1 & 106.9 & 895.99 & 1050.26 & 0.107 \\
\hline & D2 & 112.0 & 931.46 & 1069.30 & 0.039 \\
\hline & D3 & 111.1 & 917.61 & 1066.85 & 0.033 \\
\hline & D4 & 110.7 & 924.72 & 1072.92 & 0.050 \\
\hline & D5 & 110.6 & 913.36 & 1048.20 & 0.034 \\
\hline \multirow{5}{*}{$\begin{array}{l}\text { Gas } \\
\text { pores }\end{array}$} & G1 & 108.7 & 928.99 & 1140.25 & 0.052 \\
\hline & G2 & 114.9 & 997.75 & 1165.43 & 0.056 \\
\hline & G3 & 110.3 & 958.5 & 1159.15 & 0.051 \\
\hline & G4 & 110.6 & 977.78 & 1124.46 & 0.058 \\
\hline & G5 & 107.7 & 959.21 & 1133.04 & 0.071 \\
\hline \multirow{5}{*}{$\begin{array}{l}\text { LOF } \\
\text { defects }\end{array}$} & L1 & 73.3 & 606.65 & 638.36 & 0.013 \\
\hline & L2 & 77.5 & 617.88 & 670.37 & 0.014 \\
\hline & L3 & 70.8 & 568.88 & 634.56 & 0.017 \\
\hline & L4 & 71.4 & 567.82 & 630.03 & 0.016 \\
\hline & L5 & 80.2 & 622.6 & 695.20 & 0.016 \\
\hline
\end{tabular}




\section{Discussion}

This research showed the correlations between processing parameters and porosity characteristics by developing an empirical process model. The aim was to find suitable parameters for high spherical porosity for the application in FGM to evade the disadvantages of porosity achieved through LOF defects and reduce the stiffness.

To do so, three experimental runs were conducted. It could be shown that the volume energy density influences the relative density and the sphericity of pores and therefore the type of porosity. Low energy densities result in insufficient melting of the powder layer and thus a lack of fusion between adjacent layers. Consequently, large, irregular shaped LOF defects can be observed. On the other hand, high energy inputs lead to large melt pools, evaporation and keyhole formation. Gas bubbles are entrapped in the melt and due to high solidification rates, they cannot escape before solidification and remain in the part in form of spherical pores [40]. However, the influences of the process parameters included in the volume energy density (see equation (6)) on the porosity are quite different, as it was also stated by Elsayed et al. [36]. Hence, although it might be convenient, when investigating the PBFLB/M process, one should not focus on this metric alone but rather should take a closer look on the underlying parameters and their interactions.

As this study focused on the spherical gas porosity, the parameter ranges for the main and verification runs were adjusted so that porosity due to LOF defects was excluded. An essential finding was that there is an optimum area for maximum gas porosity within the investigated parameter range of laser power and scanning speed. At this point, it should be noted that the fitted model is only valid in the examined parameter space. It was shown, that gas porosity increases with increasing laser power and scanning speed up to a certain point and then decreases with further increasing of these parameters, i.e. there is an optimum region as shown in Fig. 6. The scanning speed largely determines the cooling rate since with increasing scanning speed the time for which a certain area is exposed to the laser beam decreases. For a slow scanning speed and small cooling rate, the gas has more time to escape the melt. If the scanning speed is high enough, keyhole formation and evaporation and thus pore formation can be avoided due to the lower volume energy density. Regarding the laser power, the influence on the volume energy density and resulting melt behavior is also underlined by the results. While too high laser powers lead to larger melt pools and lower melt viscosity due to high melt temperature [44], allowing the entrapped gas to escape, a laser power below a scanning speed dependent threshold is insufficient to cause evaporation and thus gas porosity. Within the investigated parameter range, the hatch spacing showed no significant influence on the relative density. This could be explained by the thermal behavior of the processed Ti-6Al-4V. Due to its relatively poor thermal conductivity, the formed melt pool is much larger than the laser spot size and also larger than the investigated hatch spacings. Consequently, there are no unmelted voids between adjacent scan tracks even at large hatch spacings and therefore the hatch spacing has less influence on pore formation. These results, however, are only valid within the investigated parameter window.

In general, the achievable maximum amount of gas porosity is much smaller than it is for the LOF type of porosity. First, this can be attributed to the parameter interactions described before that lead to a limited area were high gas porosity can be realized. Another aspect to mention is that while gaseous pores typically have sizes of under $100 \mu \mathrm{m}$ [38], mostly of $5 \mu \mathrm{m}-20 \mu \mathrm{m}$ [45], LOF defects can reach sizes of $100 \mu \mathrm{m}-150 \mu \mathrm{m}$ [40] and can be of branched and irregular morphology. Due to their overall larger size, LOF defects can therefore yield higher part porosities that are also only limited by the mechanical stability of the part.

Besides the porosity itself, also the pore characteristics, two-dimensional sphericityequivalent and mean pore area, were evaluated. The sphericity-equivalent only showed dependence on the laser power within the evaluated parameter range. A high gas porosity is associated with a high mean sphericity-equivalent of the pores because only gas pores are present within the specimens manufactured with the respective high volume energy density parameter combinations. As stated by Kasperovich et al., the two dimensional circularity of pores, that is similar to the sphericity-equivalent applied in this work, generally shows the same trends as the threedimensional sphericity [41]. Accordingly, it is assumed that the sphericity-equivalent represents the behavior and dependencies of the true sphericity.

The pore size increases with increasing laser power and decreasing hatch spacing and thus with increasing volume energy input. A higher energy input leads to increased evaporation and could therefore promote pore formation. In the 
investigated parameter range, neither a maximum nor a minimum pore size could be obtained according to the models prediction since the significant effects were of linear nature. Presumably, a widening of the parameter window would provide further information in this regard.

The feasibility of manufacturing parts with locally adjusted porosity, i.e. cylindrical specimens with dense skin and porous core could be demonstrated in this work. Based on these results, the targeted variation of porosity within a part can be transferred to more complex parts with also more than two levels of porosity in the future. A prerequisite is the local adjustability of the processing parameters that is not given by default to the necessary degree in typical preprocessing software. The technique of dividing the actual part into sub-units to which the respective parameter sets are then assigned is time-consuming and error-prone. To realize such complex parts, further development of preprocessing software is therefore necessary.

The tensile tests showed significant differences between the different specimen modifications. The specimens with gas porous core showed the highest strength as well as the highest elongation but without a change of the elastic modulus. The high strength and elongation despite the presence of a high amount of defects can be explained by two aspects. First, round pores are less detrimental for the mechanical properties compared to LOF defects [40-41]. A second aspect to consider is the microstructure that can be influenced by variation of the processing parameters as it depends on the energy input, the resulting cooling rate as well as the melt pool size $[6,43]$. It is therefore likely that due to the high energy input und lower cooling rates for the gas porous specimens, a higher amount of $\beta$-phase and less $\alpha$-martensite was generated. A small amount of $\beta$-phase in as-built specimens was also detected by Yang et al. [46]. However, this aspect needs further microstructural investigation in future works. Moreover, a subsequent heattreatment could further adjust the microstructure and mechanical properties [47].

The results also imply that a porosity of nearly $6 \%$ in the core resulting in even less porosity based on the entire part is not enough to significantly influence the stiffness of a specimen. According to equation (2) the overall mean relative density of $96.11 \%$ in the cylindrical specimen should lead to a stiffness reduction of $7.6 \%$. The fact that such a decrease of the elastic modulus could not be observed could be attributed to the realization of only a porous core with a dense shell that increases the stiffness instead of a completely porous part. Another possible explanation is the overall relatively low porosity compared to the amount that would be necessary to obtain the stiffness of human bone as given by Yadroitsava et al. [30]. To obtain large changes of stiffness, the relative density therefore has to be significantly lower. This can be achieved by the implementation of LOF defects and therefore, here a significant decrease of stiffness (32.2\%) could be observed. This result even exceeds the prediction based on equation (2) for an absolute porosity of $15 \%$, i.e. a decrease by $27.8 \%$. However, this reduction of stiffness comes at the cost of strongly reduced ductility and strength. This can be attributed to the notch effect of the irregular shaped LOF defects that often have sharp edges that are likely to function as crack initiation sites due to stress concentration [40]. In terms of spherical gas porosity, based on the results of this study, stiffness reduction may not be a suitable application. Nevertheless, the superior mechanical properties of the specimens with a gas porous core suggest that an implementation in load-bearing lightweight applications could be suitable. Here, weight reduction without stiffness reduction would be of great interest. Since the parts in this study were of small size and simple geometry, the scalability of the results should be further investigated.

\section{Conclusions}

In this work, an empirical process model for spherical porosity in additively manufactured $\mathrm{Ti}-$ $6 \mathrm{Al}-4 \mathrm{~V}$ was developed. Based on the model predictions a parameter combination for high spherical porosity was selected for application in functionally graded demonstration parts. These could be successfully built and served as a basis for the subsequently manufactured tensile test specimens. Tensile tests were conducted to investigate the influence of the graded porosity on tensile properties. The following conclusions can be given:

- $\quad$ There is a strong correlation of volume energy density, relative density and pore sphericity. A two-dimensional sphericity-equivalent of $<0.89$ was found to indicate LOF porosity, whereas a value $>0.91$ stands for spherical gas porosity. Between these values, a transition area with both types of porosity could be found. An increasing volume energy density leads to an increasing 2D sphericityequivalent. The minimum relative density 
achievable by LOF porosity is significantly higher than the one achievable by gas porosity.

- Empirical models were fitted for the relative density as well as the $2 \mathrm{D}$ sphericity-equivalent and the mean pore area. In all models, the laser power had the strongest influence on the respective target size. The porosity can therefore most effectively be adjusted by tuning the applied laser power.

- For maximized spherical gas porosity, the parameter combination of $P=189 \mathrm{~W}, v=$ $375 \mathrm{~mm} / \mathrm{s}$ and $h=150 \mu \mathrm{m}$ for a layer thickness of $30 \mu \mathrm{m}$ was determined, leading to a predicted relative density of $94.06 \%$.

- The feasibility of manufacturing parts with locally adjusted porosity could be demonstrated for cylindrical specimens with a porous core and a dense skin.

- Tensile tests revealed that specimens with a gas porous core were superior to fully dense specimens regarding their strength and elongation at break. However, the elastic modulus did not change by implementing gas porosity. In contrast, the realization of a core with LOF defects led to a decrease of the elastic modulus from $110.0 \mathrm{GPa}$ for fully dense specimen to $74.6 \mathrm{GPa}(32.2 \%)$, but at the cost of significantly reduced strength and elongation.

This work showed that a significant stiffness reduction is possible by the local generation of LOF defects rather than by spherical gas porosity. Due to the superior mechanical properties of specimens with gas porous core, this is suggested for lightweight applications, where a high stiffness is important.

\section{Declarations}

\section{Funding}

This research did not receive any specific grant from funding agencies in the public, commercial, or not-for-profit sectors.

\section{Conflicts of interest}

The authors declare no conflict of interest.

\section{Availability of data and material}

Data will be available upon request.

\section{Code availability}

Not applicable.

\section{Author contributions}

Nicole Emminghaus: conception; analysis; interpretation; visualization; writing - original draft preparation

Johanna Paul: conception; executive trials; analysis; interpretation; visualization

Christian Hoff: writing - review and editing; supervision

Jörg Hermsdorf: writing - review and editing; supervision

Stefan Kaierle: writing - review and editing; supervision

\section{References}

[1] Harrysson OL, Cansizoglu O, Marcellin-Little DJ, Cormier DR, West II HA (2008) Direct metal fabrication of titanium implants with tailored materials and mechanical properties using electron beam melting technology. Materials Science and Engineering: C 28(3):366-373. https://doi.org/ \%2010.1016/j.msec.2007.04.022

[2] Cronskär M, Rännar LE, Bäckström M (2013) Production of Customized Hip Stem Prostheses: A Comparison Between Machining and Additive Manufacturing. Rapid prototyping journal 19(5):365-372. https://doi.org/10.1108/RPJ-072011-0067

[3] Jardini AL, Larosa MA, de Carvalho Zavaglia CA, Bernardes LF, Lambert CS, Kharmandayan P, Calderoni D, Maciel Filho R (2014) Customised titanium implant fabricated in additive manufacturing for craniomaxillofacial surgery: This paper discusses the design and fabrication of a metallic implant for the reconstruction of a large cranial defect. Virtual and physical prototyping 9(2):115-125. https://doi.org/10.1080/17452759. 2014.900857

[4] Merkt S, Kleyer A, Hueber AJ (2014) The Additive Manufacture of Patient-tailored Finger Implants: Feasibility study: implants based on XtremeCT technique. Laser Technik Journal 11(2):54-56. https://doi.org/10.1002/latj.201400029

[5] Santecchia E, Spigarelli S, Cabibbo M (2020) Material Reuse in Laser Powder Bed Fusion: Side Effects of the Laser-Metal Powder Interaction. Metals 10(3):341. https://doi.org/10.3390/ met10030341

[6] Liu S, Shin YC (2019) Additive manufacturing of Ti6Al4V alloy: A review. Materials \& Design 164:107552.

https://doi.org/10.1016/j.matdes.2018.107552

[7] Tian Z, Zhang C, Wang D, Liu W, Fang X, Wellmann D, Zhao Y, Tian Y (2020) A review on laser powder bed fusion of inconel 625 nickelbased alloy. Applied Sciences 10(1):81. https://doi.org/10.3390/app1001008 
[8] Yan Q, Song B, Shi Y (2020) Comparative study of performance comparison of AlSi10Mg alloy prepared by selective laser melting and casting. Journal of Materials Science \& Technology 41:199208. https://doi.org/10.1016/j.jmst.2019.08.049

[9] Zhang WN, Wang LZ, Feng ZX, Chen YM (2020) Research progress on selective laser melting (SLM) of magnesium alloys: A review. Optik 207:163842. https://doi.org/10.1016/j.ijleo.2019. 163842

[10] Brandl E, Heckenberger U, Holzinger V, Buchbinder D (2012) Additive manufactured AISi10Mg samples using Selective Laser Melting (SLM): Microstructure, high cycle fatigue, and fracture behavior. Materials \& Design 34:159-169. https://doi.org/10.1016/j.matdes.2011.07.067

[11] Asgari H, Baxter C, Hosseinkhani K, Mohammadi M (2017) On microstructure and mechanical properties of additively manufactured AISi10Mg_200C using recycled powder. Materials Science and Engineering: A 707:148-158. https://doi.org/10.1016/j.msea.2017.09.041

[12] Lutter-Günther M, Gebbe C, Kamps T, Seidel C, Reinhart G (2018) Powder recycling in laser beam melting: strategies, consumption modeling and influence on resource efficiency. Production Engineering 12(3-4):377-389. https://doi.org/\%2010.1007/s11740-018-0790-7

[13] Cordova L, Campos M, Tinga T (2019) Revealing the effects of powder reuse for selective laser melting by powder characterization. Jom 71(3):1062-1072. https://doi.org/10.1007/s11837018-3305-2

[14] Heiden MJ, Deibler LA, Rodelas JM, Koepke JR, Tung DJ, Saiz DJ, Jared BH (2019) Evolution of 316L stainless steel feedstock due to laser powder bed fusion process. Additive Manufacturing 25:84103. https://doi.org/10.1016/j.addma.2018.10.019

[15] Agius D, Kourousis KI, Wallbrink C (2018) A review of the as-built SLM Ti-6Al-4V mechanical properties towards achieving fatigue resistant designs. Metals 8(1):75. https://doi.org/10.3390/ met8010075

[16] Shipley H, McDonnell D, Culleton M, Coull R, Lupoi R, O'Donnell G, Trimble D (2018) Optimisation of process parameters to address fundamental challenges during selective laser melting of Ti-6Al$4 \mathrm{~V}$ : A review. International Journal of Machine Tools and Manufacture 128:1-20. https://doi.org/ 10.1016/j.ijmachtools.2018.01.003

[17] Donachie MJ (2000) Titanium: a technical guide. ASM international.

[18] Leyens C, Peters M (2003) Titanium and Titanium Alloys: Fundamentals and Applications, Wiley$\mathrm{VCH}$, Weinheim.

[19] Cui C, Hu B, Zhao L, Liu S (2011) Titanium alloy production technology, market prospects and industry development. Materials \& Design 32(3):1684-1691. https://doi.org/10.1016/j.matdes. 2010.09.011
[20] Krishna BV, Bose S, Bandyopadhyay A (2007) Low stiffness porous $\mathrm{Ti}$ structures for load-bearing implants. Acta biomaterialia 3(6):997-1006. https://doi.org/10.1016/j.actbio.2007.03.008

[21] Bhattarai SR, Khalil KAR, Dewidar M, Pyoung HH, Ho KY, Kim HY (2008) Novel production method and in vitro cell compatibility of porous Ti-6Al-4V alloy disk for hard tissue engineering. J. Biomed. Mater. Res. A 86:289-299. https://doi.org/ 10.1002/jbm.a.31490

[22] Wolff J (1893) Das Gesetz der Transformation der Knochen. DMW-Deutsche Medizinische Wochenschrift 19(47):1222-1224.

[23] Oh IH, Nomura N, Masahashi N, Hanada S (2003) Mechanical properties of porous titanium compacts prepared by powder sintering. Scripta Materialia 49(12):1197-1202. https://doi.org/10.1016/ j.scriptamat.2003.08.018

[24] Pałka K, Pokrowiecki R (2018) Porous Titanium implants: A review. Advanced Engineering Materials 20(5):1700648. https://doi.org/10.1002/ adem.201700648

[25] Yuan L, Ding S, Wen C (2019) Additive manufacturing technology for porous metal implant applications and triple minimal surface structures: A review. Bioactive Materials 4:56-70. https://doi.org/10.1016/j.bioactmat.2018.12.003

[26] Ran Q, Yang W, Hu Y, Shen X, Yu Y, Xiang Y, Cai K (2018) Osteogenesis of 3D printed porous Ti6Al4V implants with different pore sizes. Journal of the Mechanical Behavior of Biomedical Materials 84:1-11. https://doi.org/10.1016/j.jmbbm.2018.04. 010.

[27] Gibson LJ, Ashby MF (1999) Cellular solids: structure and properties. Cambridge university press.

[28] Anthoine A. (2010) Second-order homogenisation of functionally graded materials. International Journal of Solids and Structures 47(11-12):14771489. https://doi.org/10.1016/j.ijsolstr.2010.02.004

[29] Bertol LS, Júnior WK, d. Silva FP, Aumund-Kopp C (2010) Medical design: Direct metal laser sintering of Ti-6Al-4V. Materials \& Design 31(8):3982-3988. https://doi.org/10.1016/j.matdes.2010.02.050

[30] Yadroitsava I, d. Plessis A, Yadroitsev I (2019) Bone regeneration on implants of titanium alloys produced by laser powder bed fusion: A review. Titanium for Consumer Applications, pp. 197-233. https://doi.org/10.1016/B978-0-12-8158203.00016-2

[31] Mahmoud D, Elbestawi MA (2017) Lattice Structures and Functionally Graded Materials Applications in Additive Manufacturing of Orthopedic Implants: A Review. Journal of Manufacturing and Materials Processing 1(2):13. https://doi.org/10.3390/jmmp1020013

[32] Dhiman S, Sidhu SS, Bains PS (2019) Mechanobiological assessment of Ti-6Al-4V fabricated via selective laser melting technique: a 
review. Rapid Prototyping Journal 25(7):12661284. https://doi.org/10.1108/RPJ-03-2019-0057

[33] Parthasarathy J, Starly B, Raman S (2011) A design for the additive manufacture of functionally graded porous structures with tailored mechanical properties for biomedical applications. Journal of Manufacturing Processes 13(2):160-170. https://doi.org/10.1016/j.jmapro.2011.01.004

[34] Wally ZJ, v. Grunsven W, Claeyssens F, Goodall R, Reilly GC (2016) Porous Titanium for Dental Implant Applications. Metals 6(5):97. https://doi.org/10.3390/met5041902

[35] Yang L, Yan C, Fan H, Li Z, Cai C, Chen P, Shi Y, Yang S (2019) Investigation on the orientation dependence of elastic response in Gyroid cellular structures. Journal of the mechanical behavior of biomedical materials 90:73-85. https://doi.org/ 10.1016/j.jmbbm.2018.09.042

[36] Elsayed M, Ghazy M, Youssef Y, Essa K (2019) Optimization of SLM process parameters for Ti6Al4V medical implants. Rapid Prototyping Journal 25(3): 433-447. https://doi.org/10.1108/ RPJ-05-2018-0112

[37] Lin WS, Starr TL, Harris BT, Zandinejad A, Morton D () Additive Manufacturing Technology (Direct Metal Laser Sintering) as a Novel Approach to Fabricate Functionally Graded Titanium Implants: Preliminary Investigation of Fabrication Parameters. The International Journal of Oral and Maxillofacial Implants 28(6):1490-1495. https://doi.org/10.11607/jomi.3164

[38] Zhang B, Li Y, Bai Q (2017) Defect formation mechanisms in selective laser melting: a review. Chinese Journal of Mechanical Engineering 30(3):515-527. https://doi.org/10.1007/s10033017-0121-5

[39] Kyogoku H, Ikeshoji TT (2020) A review of metal additive manufacturing technologies: Mechanism of defects formation and simulation of melting and solidification phenomena in laser powder bed fusion process. Mechanical Engineering Reviews 7(1):19-00182. https://doi.org/10.1299/mer.1900182

[40] Vilaro T, Colin C, Bartout JD (2011) As-fabricated and heat-treated microstructures of the Ti-6Al-4V alloy processed by selective laser melting. Metallurgical and materials transactions $\mathrm{A}$ 42(10):3190-3199. https://doi.org/10.1007/s11661011-0731-y

[41] Kasperovich G, Haubrich J, Gussone J, Requena $G$ (2016) Correlation between porosity and processing parameters in TiAl6V4 produced by selective laser melting. Materials \& Design 105:160-170. https://doi.org/10.1016/j.matdes. 2016.05.070

[42] Kimura T, Nakamoto T (2016) Microstructures and mechanical properties of A356 (AISi7Mg0. 3) aluminum alloy fabricated by selective laser melting. Materials \& Design 89:1294-1301. https://doi.org/10.1016/j.matdes.2015.10.065

[43] Wadell H (1935) Volume, Shape and Roundness of Quartz Particles. The Journal of Geology 43(3):250-280. https://doi.org/10.1086/624298

[44] Khorasani M, Ghasemi A, Awan US, Hadavi E, Leary M, Brandt M, Littlefair G, O’Neil W, Gibson I (2020) A study on surface morphology and tension in laser powder bed fusion of Ti-6Al-4V. The International Journal of Advanced Manufacturing Technology 111(9):2891-2909. https://doi.org/ 10.1007/s00170-020-06221-w

[45] Thijs L, Verhaeghe F, Craeghs T, Van Humbeeck J, Kruth JP (2010) A study of the microstructural evolution during selective laser melting of Ti-6Al4V. Acta materialia 58(9):3303-3312. https://doi.org/10.1016/j.actamat.2010.02.004

[46] Yang J, Yu H, Yin J, Gao M, Wang Z, Zeng X (2016) Formation and control of martensite in Ti-6Al-4V alloy produced by selective laser melting. Materials \& Design 108:308-318. https://doi.org/10.1016/ j.matdes.2016.06.117

[47] Vrancken B, Thijs L, Kruth JP, Van Humbeeck J (2012) Heat treatment of Ti6Al4V produced by Selective Laser Melting: Microstructure and mechanical properties. Journal of Alloys and Compounds 541:177-185. https://doi.org/10.1016/ j.jallcom.2012.07.022 
Figures

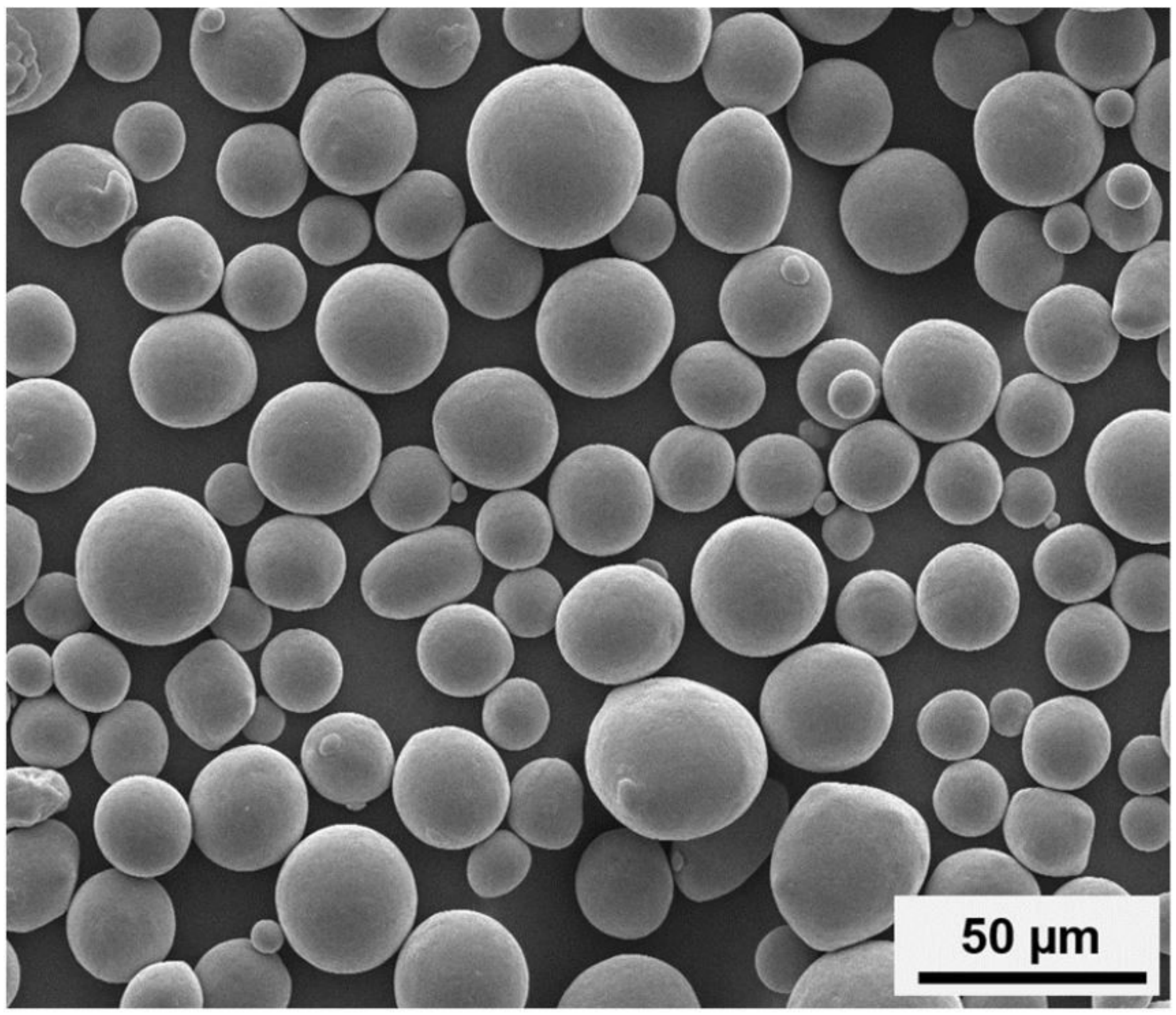

Figure 1

SEM image of used Ti-6Al-4V powder 


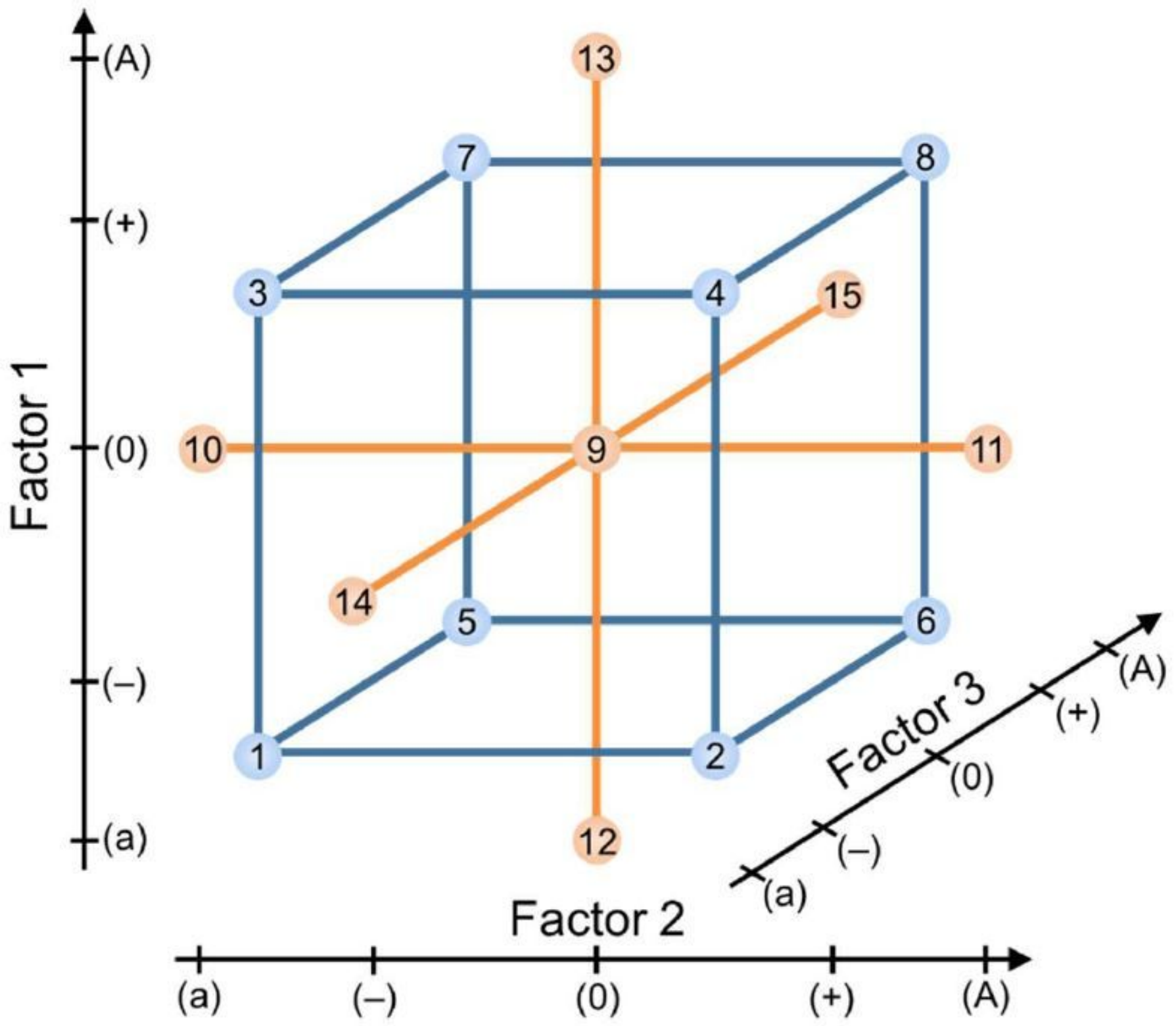

Figure 2

Central composite design with corner points (1-8), central point (9) and star points (10-15) 


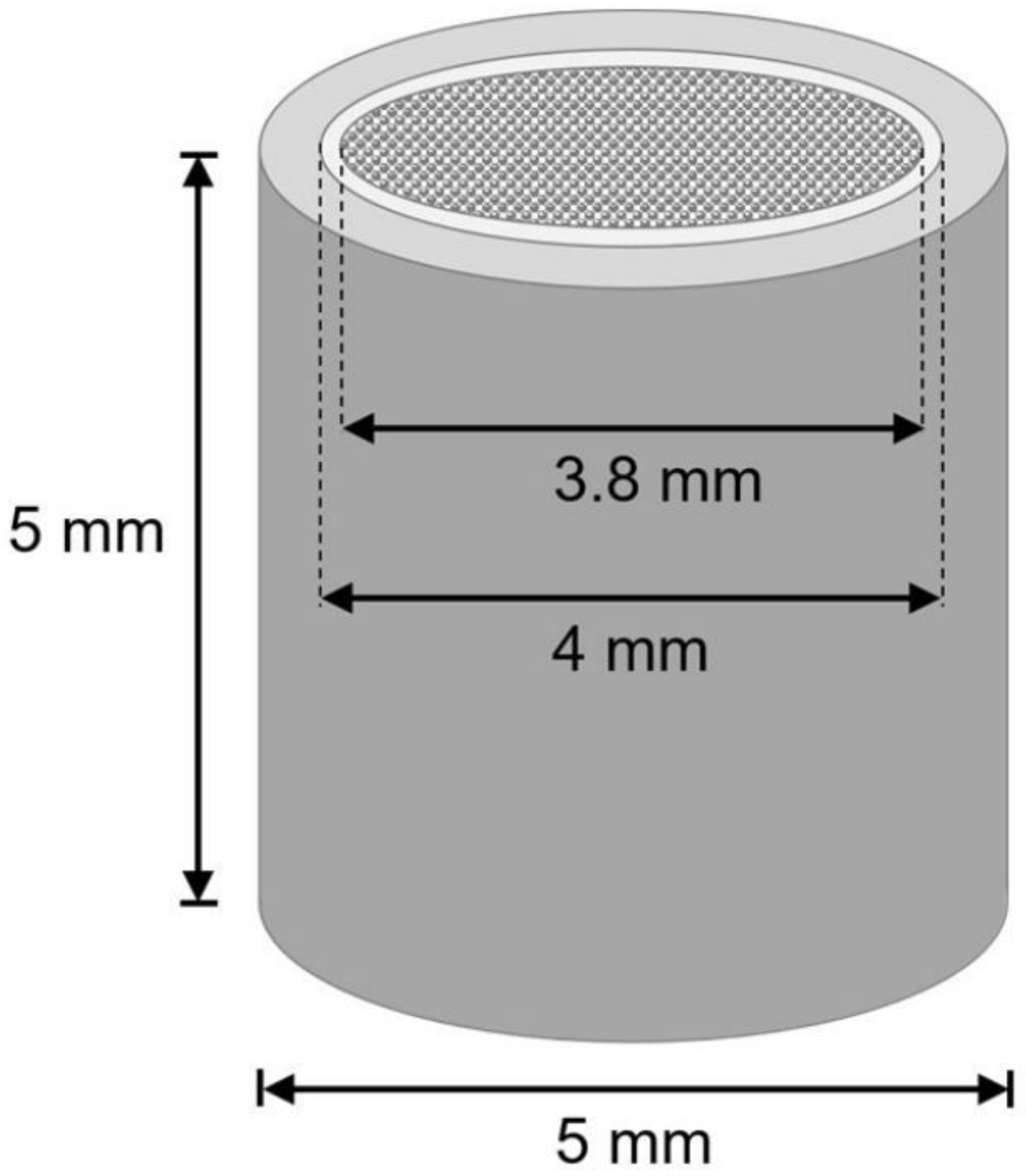

Figure 3

Geometry of cylindrical specimens with porous core and dense skin 


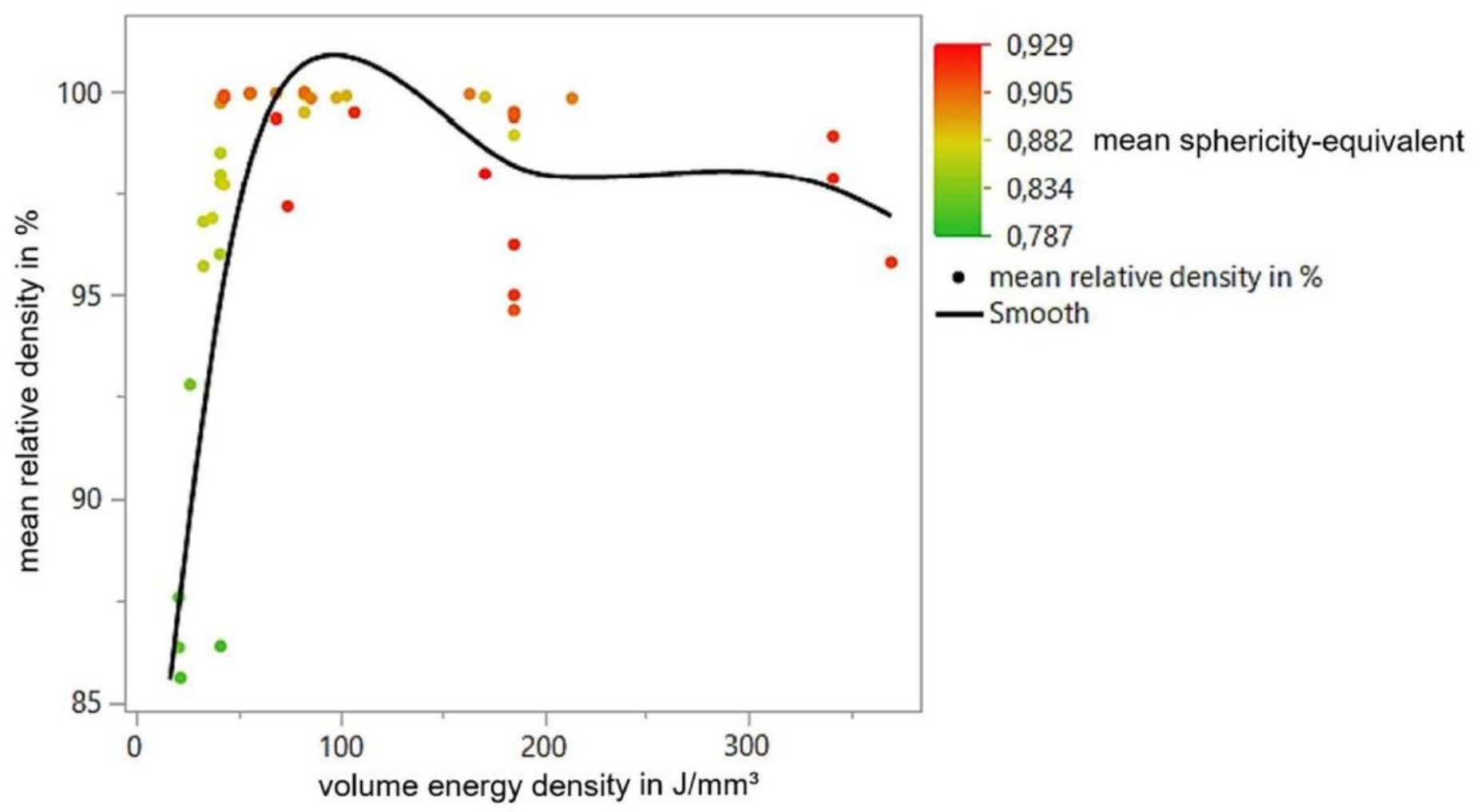

Figure 4

Mean relative density in dependence of applied volume energy density; mean sphericity-equivalent colorcoded, cubic spline with lambda $=0.05$ used as smoother

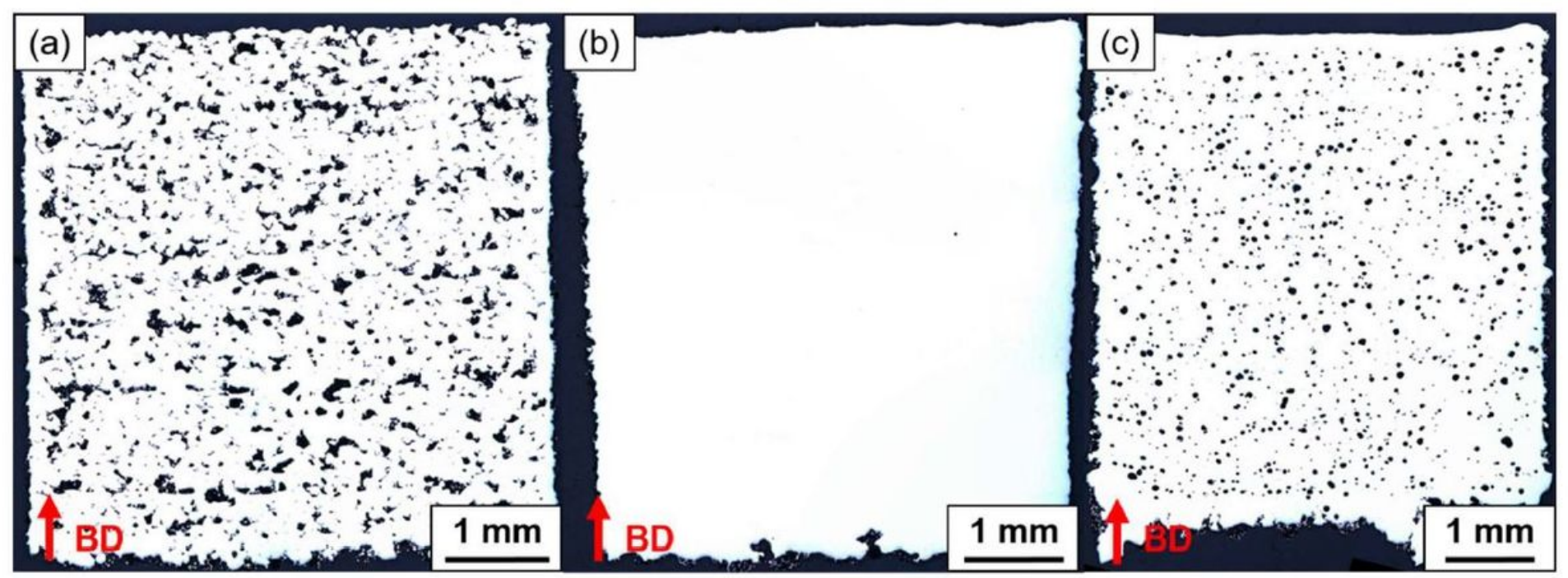

Figure 5

Light microscopy images of cross-sections: (a) LOF porosity ( $P=100 \mathrm{~W}, \mathrm{v}=1350 \mathrm{~mm} / \mathrm{s}, \mathrm{h}=120 \mu \mathrm{m}),(\mathrm{b})$ nearly fully dense $(P=200 \mathrm{~W}, \mathrm{v}=1350 \mathrm{~mm} / \mathrm{s}, \mathrm{h}=60 \mu \mathrm{m})$, (c) gas porosity $(P=100 \mathrm{~W}, \mathrm{v}=300 \mathrm{~mm} / \mathrm{s}, \mathrm{h}=$ $60 \mu \mathrm{m})$; red arrow indicates build direction. 

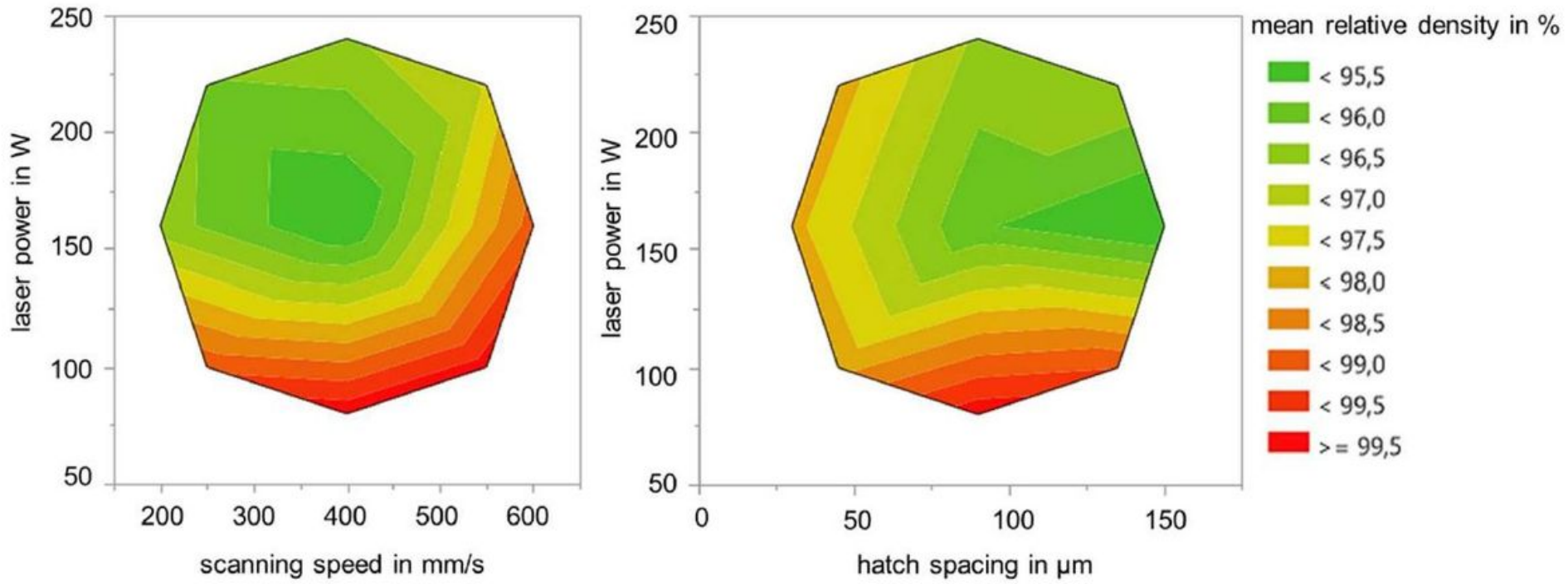

Figure 6

Contour plots for mean relative density in dependence of laser power, scanning speed and hatch spacing 


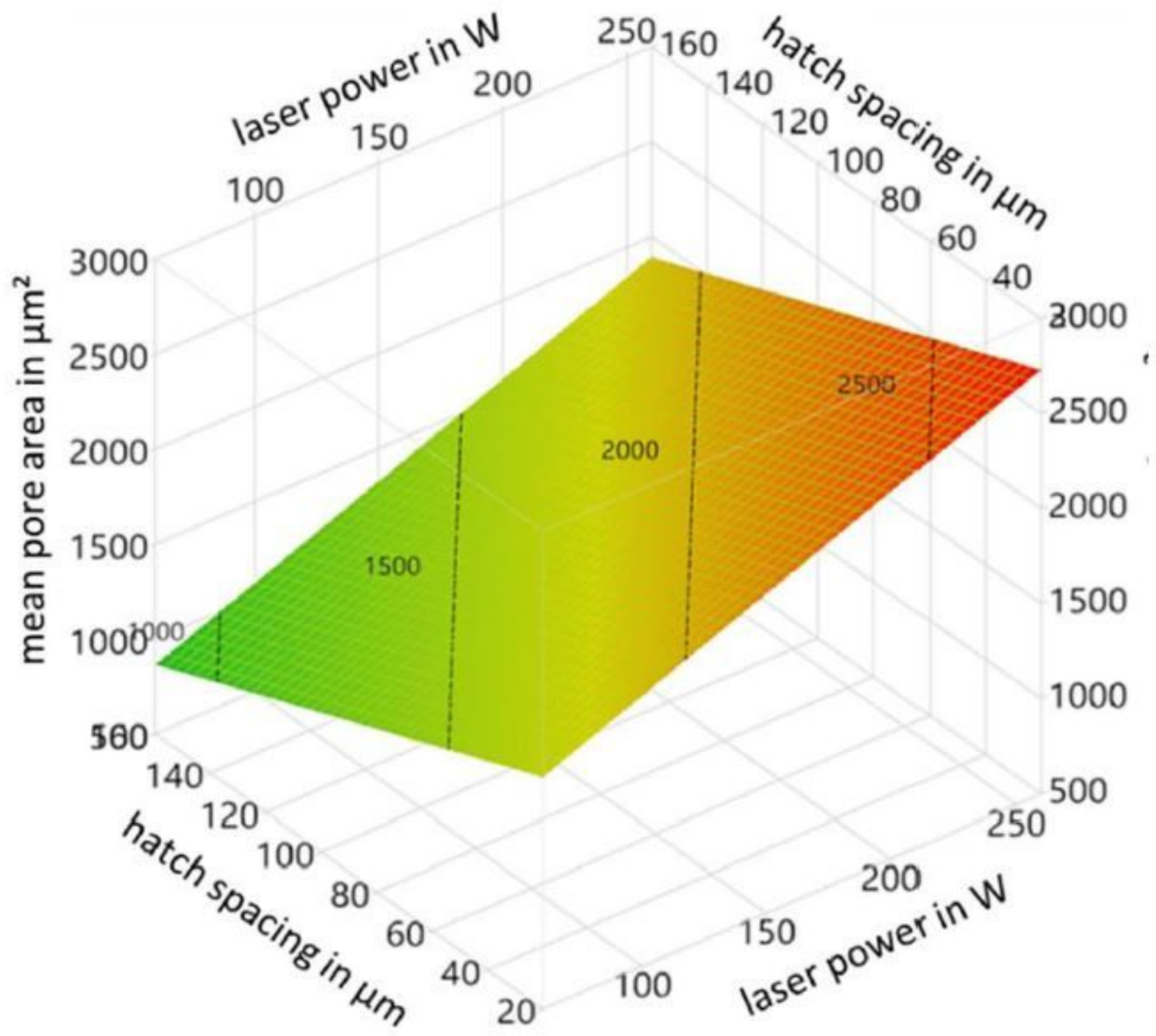

Figure 7

Response surface of mean pore area in dependence of laser power and hatch spacing 

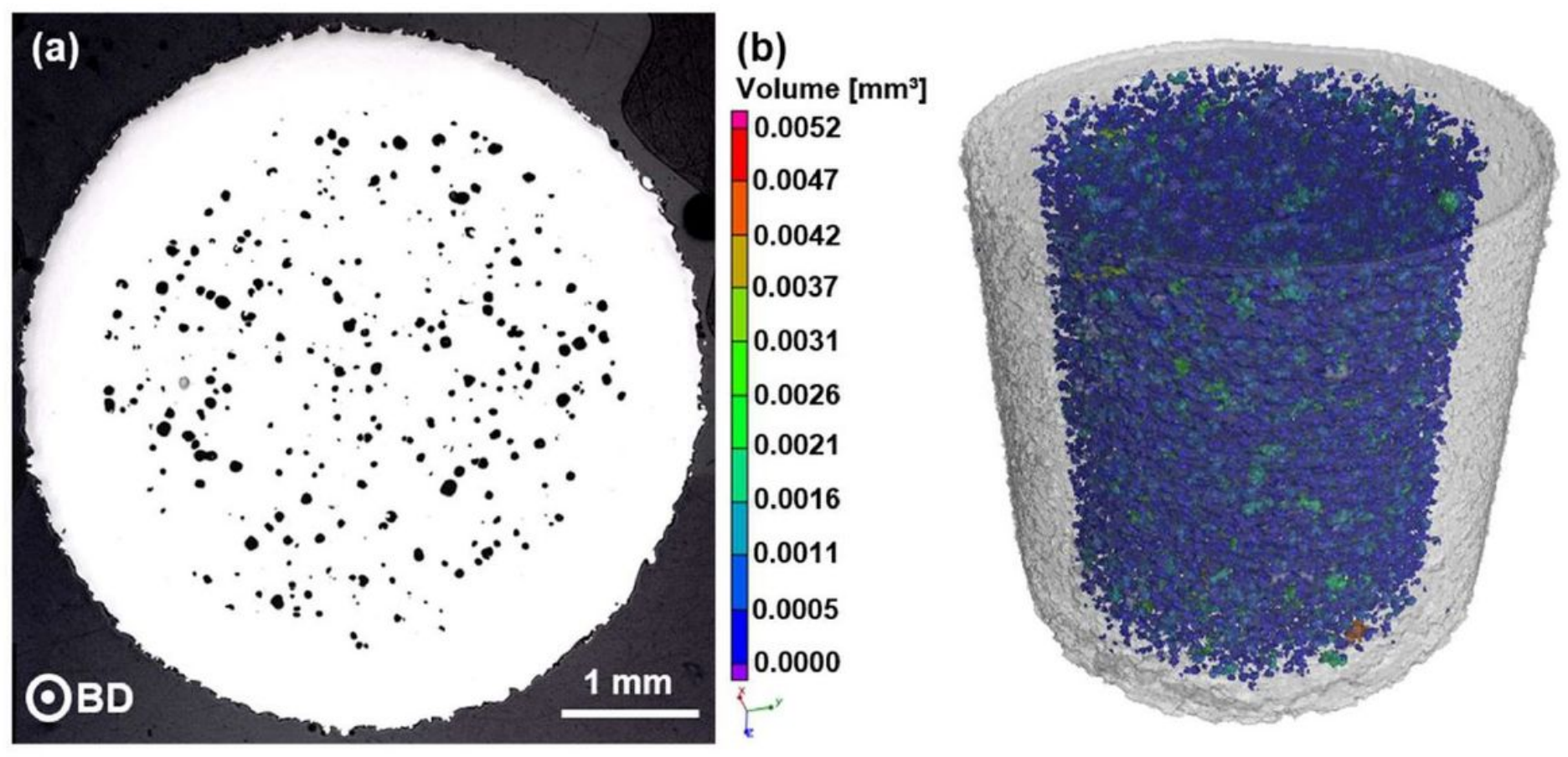

Figure 8

FGM demonstrator part: (a) Cross-section perpendicular to build direction; (b) CT image with pore analysis 
(a)

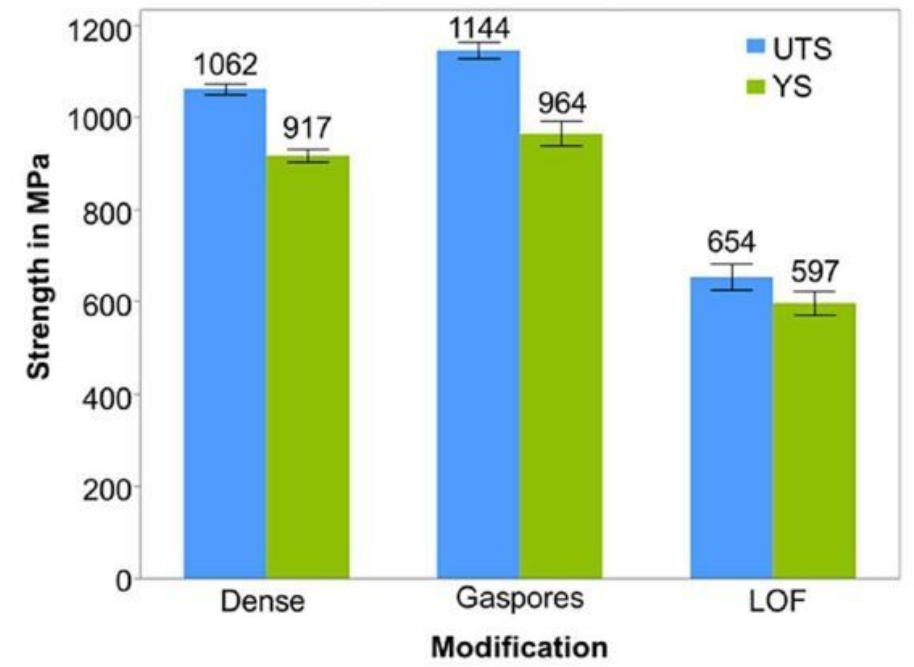

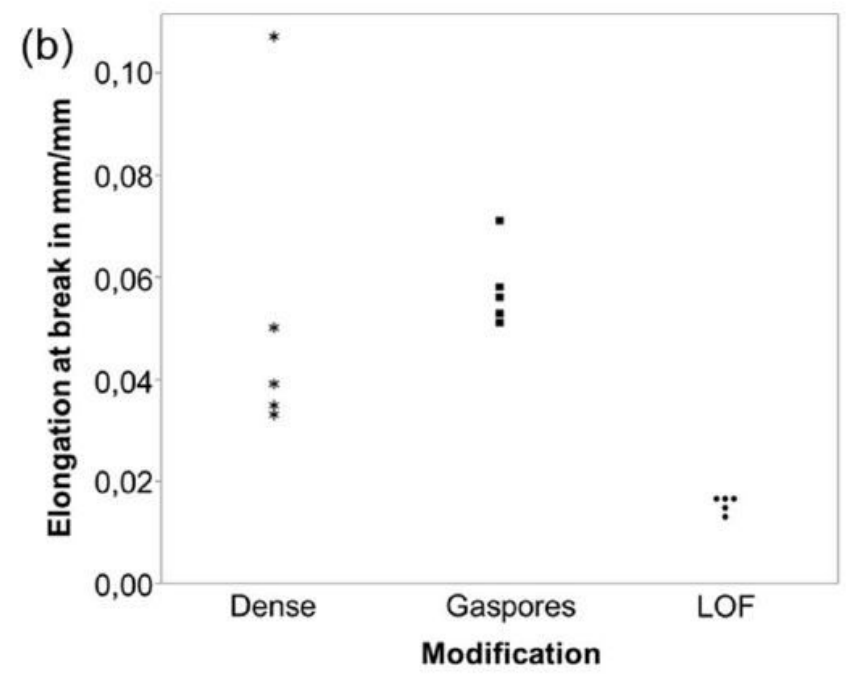

(c)

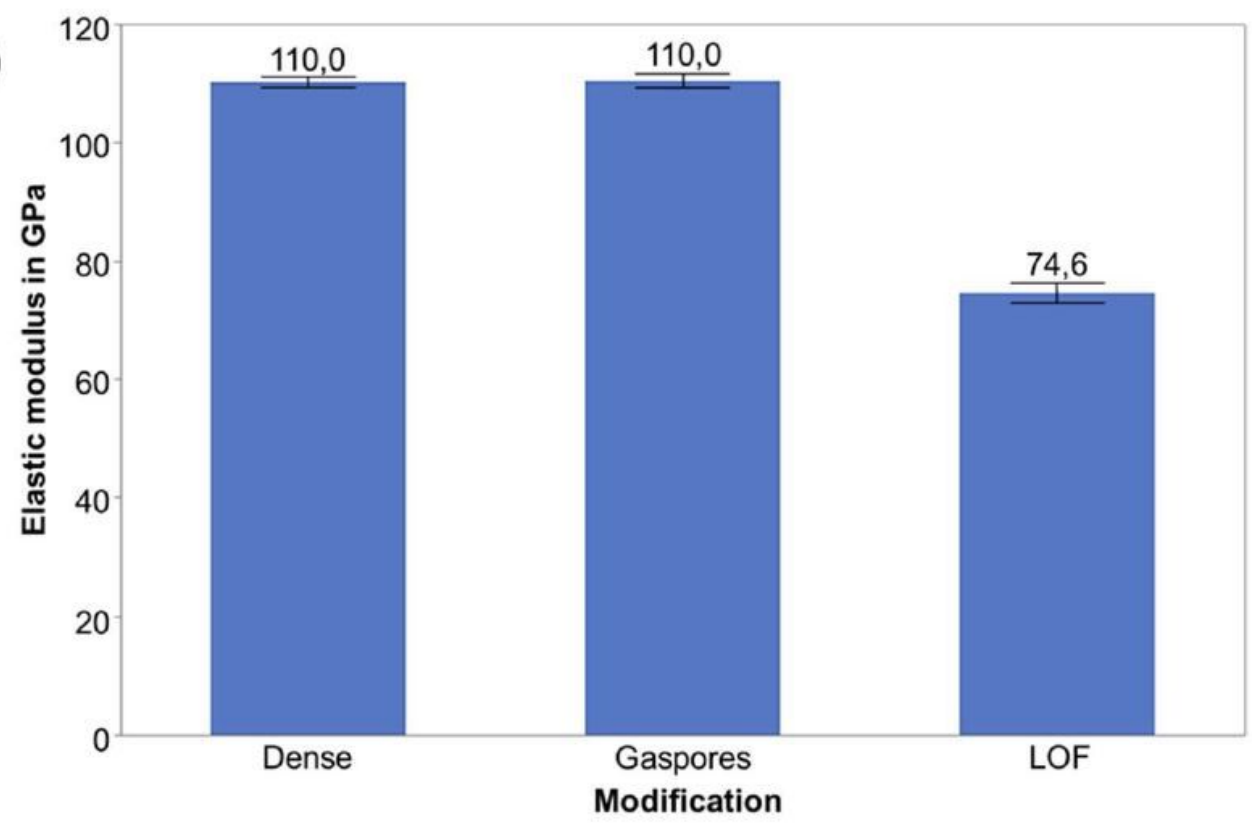

Figure 9

Tensile test results: (a) Ultimate tensile strength (UTS) and yield strength (YS) with marked standard deviation; (b) elongation at break; (c) elastic modulus with marked standard deviation 